\title{
Methodological Framework for Analysis of Buildings-Related Programs with BEAMS, 2008
}

\section{DB Elliott}

JA Dirks

DJ Hostick

September 2008

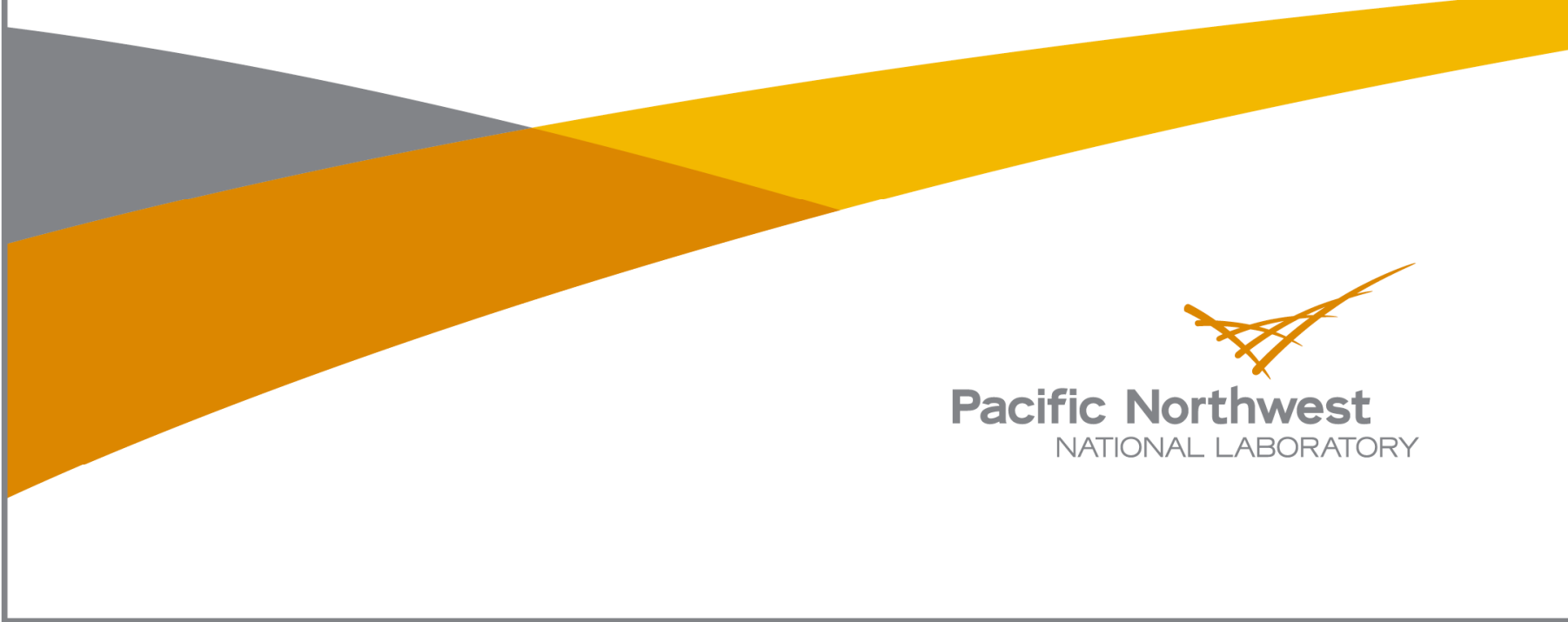




\title{
DISCLAIMER
}

This report was prepared as an account of work sponsored by an agency of the United States Government. Neither the United States Government nor any agency thereof, nor Battelle Memorial Institute, nor any of their employees, makes any warranty, express or implied, or assumes any legal liability or responsibility for the accuracy, completeness, or usefulness of any information, apparatus, product, or process disclosed, or represents that its use would not infringe privately owned rights. Reference herein to any specific commercial product, process, or service by trade name, trademark, manufacturer, or otherwise does not necessarily constitute or imply its endorsement, recommendation, or favoring by the United States Government or any agency thereof, or Battelle Memorial Institute. The views and opinions of authors expressed herein do not necessarily state or reflect those of the United States Government or any agency thereof.

\author{
PACIFIC NORTHWEST NATIONAL LABORATORY \\ operated by \\ BATTELLE \\ for the \\ UNITED STATES DEPARTMENT OF ENERGY \\ under Contract DE-AC05-76RL01830
}

Printed in the United States of America
Available to DOE and DOE contractors from the
Office of Scientific and Technical Information,
P.O. Box 62, Oak Ridge, TN 37831-0062;
ph: (865) 576-8401
fax: $(865) 576-5728$
email: reports@adonis.osti.gov

\author{
Available to the public from the National Technical Information Service, \\ U.S. Department of Commerce, 5285 Port Royal Rd., Springfield, VA 22161 \\ ph: (800) 553-6847$$
\text { fax: }(703) 605-6900
$$ \\ email: orders@ntis.fedworld.gov \\ online ordering: http://www.ntis.gov/ordering.htm
}

This document was printed on recycled paper. 


\title{
Methodological Framework for Analysis of Buildings-Related Programs with BEAMS, 2008
}

\author{
DB Elliott \\ JA Dirks \\ DJ Hostick
}

September 2008

Prepared for

the U.S. Department of Energy

under Contract DE-AC05-76RL01830

Pacific Northwest National Laboratory

Richland, Washington 99352 



\section{Executive Summary}

The U.S. Department of Energy's (DOE's) Office of Energy Efficiency and Renewable Energy (EERE) develops official "benefits estimates" for each of its major programs using its Planning, Analysis, and Evaluation (PAE) Team. PAE conducts an annual integrated modeling and analysis effort to produce estimates of the energy, environmental, and financial benefits expected from EERE's budget request. These estimates are part of EERE's budget request and are also used in the formulation of EERE's performance measures.

Two of EERE's major programs are the Building Technologies Program (BT) and the Weatherization and Intergovernmental Program (WIP). Pacific Northwest National Laboratory (PNNL) supports PAE by developing the program characterizations and other market information necessary to provide input to the EERE integrated modeling analysis as part of PAE's Portfolio Decision Support (PDS) effort. Additionally, PNNL also supports BT by providing line-item estimates for the Program's internal use. Throughout the report we refer to these programs as "buildings-related" programs because the approach is not inherently limited in application to BT or WIP.

To adequately support PAE and BT in the development of benefits inputs and estimates, PNNL communicates with the managers and Program contacts of various activities and projects in BT and WIP to determine how best to characterize their activities planned for the upcoming budget request. PNNL then analyzes these efforts in terms of target markets, market penetrations, and cost and performance parameters versus the displaced technologies. In cases where the BT or WIP activity does not easily fit into the integrated modeling framework, PNNL develops "non-integrated" estimates of energy benefits of the technologies and practices expected to result from the budget request. ${ }^{1}$ These characterizations and non-integrated modeling results are provided to PAE as inputs to the official benefits estimates developed for the federal budget. ${ }^{2}$ The supporting analysis and data obtained through the metrics effort are used to estimate and validate progress toward strategic goals and objectives within BT and WIP and to communicate the benefits of EERE projects to interested parties. PNNL also develops estimates of environmental and financial benefits related to the energy benefits for BT as part of BT's internal planning process.

PNNL uses three modeling approaches to perform these analyses. This report documents the approach and methodology used to estimate future energy, environmental, and financial benefits using one of those methods: the Building Energy Analysis and Modeling System (BEAMS). ${ }^{3}$ BEAMS is a PC-based accounting model that was built in Visual Basic by PNNL specifically for estimating the benefits of buildings-related projects. It allows various types of projects to be characterized including whole-building, envelope, lighting, and equipment projects.

\footnotetext{
1 "Non-integrated" estimates mean that the potential technological, energy, and market interactions of the technologies have not been expressly dealt with. Integrated estimates would employ a methodological approach that can simultaneously address technologies that compete for the same market or that impact the same energy service (for instance artificial lighting and "day lighting").

${ }^{2}$ See http://www1.eere.energy.gov/ba/pba/program benefits.html for annual benefits estimates.

${ }^{3}$ The other two methods for calculating impacts are a variant of the National Energy Modeling System (NEMSPNNL) and spreadsheets, and are documented in Elliott et al. 2004b.
} 
This document contains an overview section that describes the estimation process and the models used to estimate energy savings. The body of the document describes the algorithms used within the BEAMS software. This document serves both as stand-alone documentation for BEAMS, and also as a supplemental update of a previous document, Methodological Framework for Analysis of BuildingsRelated Programs: The GPRA Metrics Effort, (Elliott et al. 2004b). The areas most changed since the publication of that previous document are those discussing the calculation of lighting and HVAC interactive effects (for both lighting and envelope/whole-building projects). This report does not attempt to convey inputs to BEAMS or the methodology of their derivation. That information may be found in Baseline Inputs for BEAMS: Data Used in Preparing Methodological Framework for Analysis of Building-Related Programs: The GPRA Metrics Effort, June 2004 (Elliott et al. 2004a). 


\section{Acknowledgments}

The authors would like to acknowledge Jerry Dion, Department of Energy Building Technologies Program, for support of the work discussed in this report. We would also like to acknowledge the assistance of two people. Edward Barbour of Navigant Consulting provided valuable review of the

BEAMS algorithms, and PNNL's Sean McDonald provided helpful comments on a draft of this report. 



\section{Acronyms and Abbreviations}

AFUE

BEAMS

BT

CBECS

CFL

$\mathrm{CO}$

$\mathrm{CO} 2$

COP

DOE

EERE

$\mathrm{EF}$

EIA

FEDS

GPRA

HVAC

kBtu

MMBtu

MMTCE

MMton

NEMS

NOx

PAE

PDS

PM

PM10

PNNL

QBtu

RECS

SCOP

$\mathrm{SO} 2$

TBtu

TDM

VOC

WIP annual fuel utilization efficiency

Building Energy Analysis and Modeling System

Building Technologies Program

Commercial Buildings Energy Consumption Survey

compact fluorescent lamp

carbon monoxide

carbon dioxide

coefficient of performance

U.S. Department of Energy

Office of Energy Efficiency and Renewable Energy

energy factor

Energy Information Administration

Facility Energy Decision System

Government Performance and Results Act of 1993

Heating Ventilation and Air Conditioning

thousand Btu

million Btu

million metric tons carbon equivalent

million metric tons

National Energy Modeling System

nitrous oxides

Planning, Analysis, and Evaluation Team

Portfolio Decision Support

particulate matter

particular matter of less than 10 microns in diameter

Pacific Northwest National Laboratory

quadrillion Btu

Residential Energy Consumption Survey

seasonal coefficient of performance

sulfur dioxide

trillion Btu

Technology Development Manager

volatile organic compound

Weatherization and Intergovernmental Program 



\section{Contents}

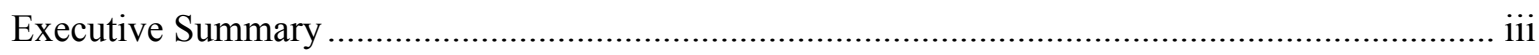

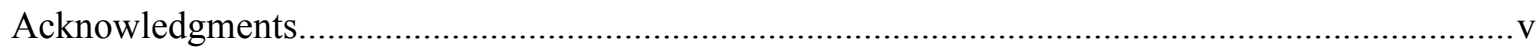

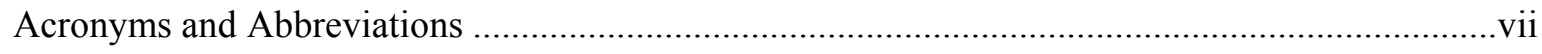

1.0 Overview of PNNL's Benefits Estimation Process ............................................................. 1.1

1.1 Estimating the Energy Savings of Buildings-Related Projects .................................... 1.1

1.2 Modeling Methods Used in Estimating Benefits ...................................................... 1.2

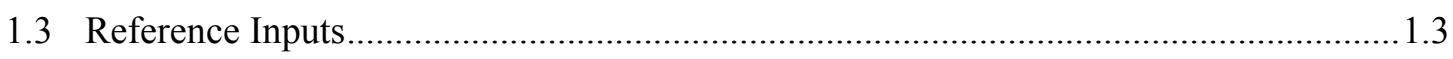

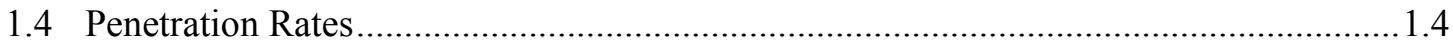

1.5 Adjustments to Estimates Due to Budget Revisions .................................................... 1.4

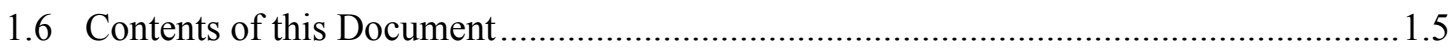

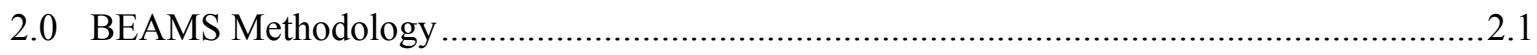

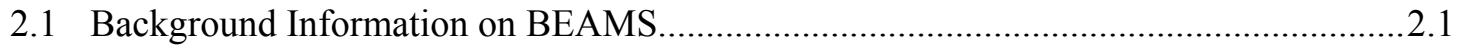

2.2 Whole-Building and Envelope Approach ..............................................................2.2

2.2.1 Determine Size of the Potential Market ...........................................................2.3

2.2.2 Determine Number of Units Affected by the Buildings-Related Project.............2.3

2.2.3 Determine Reference End-Use Loads ...............................................................

2.2.4 Determine End-Use Loads After Project Implementation ...................................2.4

2.2.5 Calculate Energy Savings............................................................................ 2.5

2.2.6 Calculate Heating and Cooling Interactive Effects Factors ................................2.6

2.2.7 Calculate Change in Space Conditioning Energy Use Due to Interactive

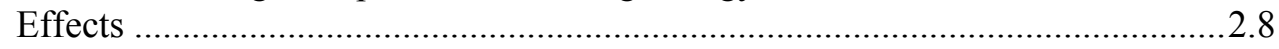

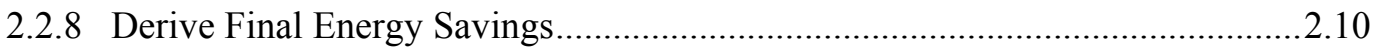

2.3 Equipment Approach............................................................................................. 2.10

2.3.1 Determine Size of Potential Market and Number of Units Affected by the Buildings-Related Project ..........................................................................2. 2.11

2.3.2 Calculate Adjustments to Potential Market and Units Affected .......................2.12

2.3.3 Determine Reference Energy Consumption of Impacted Units .........................2.14

2.3.4 Determine Energy Consumption of Impacted Units After Project

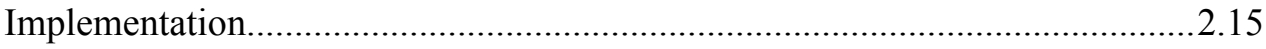

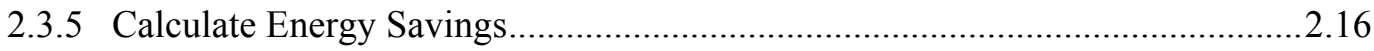

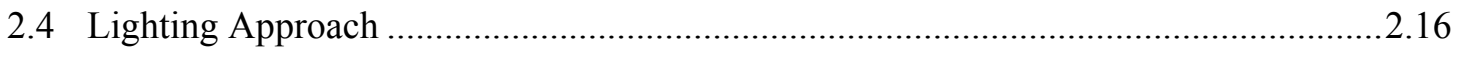

2.4.1 Determine Size of Potential Market and Number of Units Affected by the Buildings-Related Project .............................................................................2.17

2.4.2 Calculate Adjustments to the Potential Market and Units Affected...................2.18

2.4.3 Determine Reference Energy Consumption of Impacted Units .........................2.19

2.4.4 Determine Energy Consumption of Impacted Units After Project Implementation. 
2.4.5 Calculate Lighting Energy Savings ..............................................................2.21

2.4.6 Calculate Heating and Cooling Interactive Effects Factors .............................2.22

2.4.7 Calculate Change in Space Conditioning Energy Use Due to Interactive

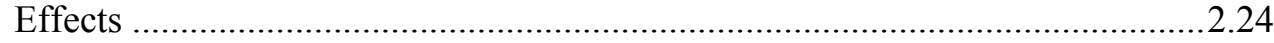

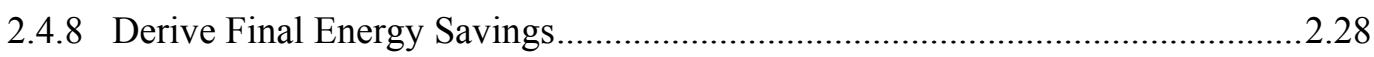

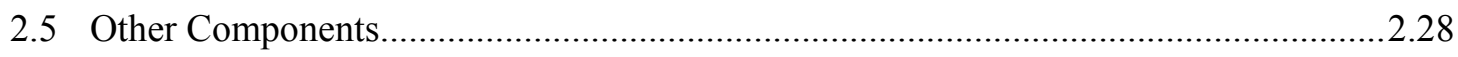

2.5.1 Calculate Primary Energy Savings ..............................................................2.2.28

2.5.2 Calculate Emissions Reductions and Energy Cost Savings ..............................2.28

2.5.3 Determine Required Investment and Non-energy Costs ...............................2.28

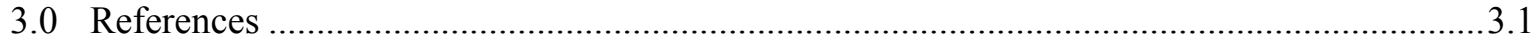




\section{Figures}

Figure 2.1. Developing the Market Segment (BEAMS) ......................................................2.2 



\subsection{Overview of PNNL's Benefits Estimation Process}

The U.S. Department of Energy's (DOE's) Office of Energy Efficiency and Renewable Energy (EERE) develops official "benefits estimates" for each of its major programs using its Planning, Analysis, and Evaluation (PAE) Team. PAE conducts an annual integrated modeling and analysis effort to produce estimates of the energy, environmental, and financial benefits expected from EERE's budget request. These estimates are part of EERE's budget request and are also used in the formulation of EERE's performance measures.

Two of EERE's major programs are the Building Technologies Program (BT) and the Weatherization and Intergovernmental Program (WIP). Pacific Northwest National Laboratory (PNNL) supports PAE by developing the program characterizations and other market information necessary to provide input to the EERE integrated modeling analysis as part of PAE's Portfolio Decision Support (PDS) effort.

Additionally, PNNL also supports BT by providing line-item estimates for the Program's internal use. Throughout the report we refer to these programs as "buildings-related" programs because the approach is not inherently limited in application to BT or WIP.

To adequately support PAE and BT in the development of benefits inputs and estimates, PNNL communicates with the managers and Program contacts of various activities and projects in BT and WIP to determine how best to characterize their activities planned for the upcoming budget request. PNNL then analyzes these efforts in terms of target markets, market penetrations, and cost and performance parameters versus the displaced technologies. In cases where the BT or WIP activity does not easily fit into the integrated modeling framework, PNNL develops "non-integrated" estimates of energy benefits of the technologies and practices expected to result from the budget request. ${ }^{1}$ These characterizations and non-integrated modeling results are provided to PAE as inputs to the official benefits estimates developed for the federal budget. ${ }^{2}$ The supporting analysis and data obtained through the metrics effort are used to estimate and validate progress toward strategic goals and objectives within BT and WIP and to communicate the benefits of EERE projects to interested parties. PNNL also develops estimates of environmental and financial benefits related to the energy benefits for BT as part of BT's internal planning process.

\subsection{Estimating the Energy Savings of Buildings-Related Projects ${ }^{3}$}

No single model or approach is capable of capturing or adequately representing the diversity of activities supported by BT and WIP (not to mention the rest of the EERE portfolio). As such, PNNL has adopted a variety of analytical approaches including macro economic models, energy accounting models, and spreadsheets. This section briefly describes the analytical approaches used to estimate energy savings for BT and WIP.

\footnotetext{
1 "Non-integrated" estimates mean that the potential technological, energy, and market interactions of the technologies have not been expressly dealt with. Integrated estimates would employ a methodological approach that can simultaneously address technologies that compete for the same market or that impact the same energy service (for instance artificial lighting and "day lighting").

${ }^{2}$ See http://www1.eere.energy.gov/ba/pba/program benefits.html for annual benefits estimates.

${ }^{3}$ Within this document, the term "project" is used in a generic sense to describe activities, technologies, or practices undertaken by BT or WIP to improve energy-efficiency in the buildings sector.
} 
PNNL assesses the benefits for a limited number of defined metrics:

- energy savings

- environmental benefits (carbon, CO2, NOX, SO2, PM10, VOC, and CO impacts)

- economic/financial metrics (consumer energy cost savings and required investment).

Energy reductions from buildings-related projects produce other benefits, including reductions in peak energy loads, enhanced security due to reduced oil demand, reduced energy costs for low-income households, and increased comfort and health in buildings; however, these are not currently measured as part of the process.

The environmental impacts that are produced as part of the estimation process are only those directly related to the burning of fossil fuels; other impacts such as land use and localized water pollution are not measured. Within the economic metrics, the consumer cost savings (or energy cost savings) simply reflect monetization of the energy savings and do not include the incremental cost of the new technology or practice; nor are they discounted. In other words, these cost savings are not "net" of the incremental investment required to capture that stream of savings. The approach for environmental impacts and consumer cost savings is based on established EERE guidance. ${ }^{4}$ Because environmental and economic benefits (energy cost savings) relate directly to projected energy savings, the balance of this overview focuses solely on estimates of energy savings.

The benefits estimates are based on an evaluation of each project to determine the impact of successful project implementation (in other words, each project is assumed to meet its stated goals). The analysis considers project goals, technology characteristics (including performance and cost), the targeted market, and project milestones. Not all activities result in readily measurable energy savings; some are intermediate or enabling technologies or practices, or are contributing to the basic understanding (a "knowledge" benefit) of energy use in the building sector.

The benefits estimates are developed based on a series of input assumptions developed project by project. These input assumptions are critical to the analysis and are developed through an iterative process with the project managers. PNNL validates these assumptions using corroborative studies or supporting analyses, and in some cases relies upon "expert judgment." Note that because BT and WIP projects are in different stages of maturity, there are varying degrees of corroborative studies available on which project information can be substantiated. Additionally, newer projects may not have estimates of future costs well-coordinated with performance estimates. For example, research projects would be expected to have more tenuous estimates of price and performance characteristics of potential products than deployment-related projects that feature products closer to market adoption. Cost and performance estimates are likely to improve as projects mature or as they near commercialization.

\subsection{Modeling Methods Used in Estimating Benefits}

PNNL calculates the buildings-related BT and WIP non-integrated estimates of benefits using one of three methods:

\footnotetext{
${ }^{4}$ Draft letter, Office of Energy Efficiency and Renewable Energy. April 1, 2002. "Performance Planning Guidance (GPRA Data Call) FY 2004-FY 2008 Budget Cycle.” U.S. Department of Energy, Washington, D.C.
} 
- Building Energy Analysis and Modeling System (BEAMS) ${ }^{5}$

- a PNNL adaptation of the National Energy Modeling System (NEMS-PNNL) ${ }^{6}$

- spreadsheets designed for a specific project.

BEAMS, the focus of this document, was built specifically for estimating the benefits of buildingsrelated projects and therefore allows various types of projects to be characterized, including wholebuilding, envelope, lighting, and equipment projects. A disadvantage of the BEAMS model is its reliance on externally determined penetration rates (i.e., fraction of sales or fraction of installed base). Analyst judgment combined with available market information is used to construct the penetration functions used to model technology or project impacts. In addition, BEAMS, absent case-specific development of custom algorithm components, cannot model equipment that competes against more than one reference equipment type (e.g., heat pumps for heating and air-conditioning competing against both a gas furnace and an electric air conditioner). We describe in detail the methodology used for deriving energy-saving estimates with BEAMS in Section 2.0 of this document.

NEMS-PNNL allows the cost and benefit characteristics of a technology and its market penetration to be modeled together. That is, this model can compete technologies based on costs, which results in a level of market penetration. However, NEMS-PNNL is designed to model specific technologies within an end use, and not the impacts of groups of interacting technologies. As such, NEMS-PNNL has difficulty representing some technologies, such as the whole-building projects (projects that simultaneously address integration and interaction of building components such as roofs, walls, and equipment).

PNNL uses spreadsheets to model projects not easily modeled in BEAMS or NEMS-PNNL. Program activities that are best suited to spreadsheets at this time include those that target a subsection of the buildings market (e.g., low-income households, which have different reference energy use assumptions), or those that are not suited to a national model (e.g., building codes, as application of codes is state or region-specific).

\subsection{Reference Inputs}

The benefits estimates represent the estimated future impacts of proposed activities presented in the President's budget submission to Congress. In order to produce estimated future impacts, a referencecase forecast must first be established. To the extent possible, the underlying assumptions about building stock forecasts, future equipment efficiencies, future market shares, and future end-use loads are applied across all tool sets (i.e., NEMS-PNNL, BEAMS, and spreadsheets). The reference-case forecast within BEAMS is produced based on data from NEMS-PNNL, the Energy Information Administration (EIA)'s Annual Energy Outlook, the "Residential Energy Consumption Survey (RECS)," and the "Commercial Buildings Energy Consumption Survey (CBECS)."7 PNNL verifies the consistency of the reference

\footnotetext{
${ }^{5}$ The BEAMS model was previously known as BESET.

${ }^{6}$ Any modification or alteration to the official NEMS model must be called out as such; for PNNL's modeling effort, the modified version used is referred to as NEMS-PNNL.

${ }^{7}$ For the Annual Energy Outlook, see: http://www.eia.doe.gov/oiaf/aeo/index.html. For RECS see: http://www.eia.doe.gov/emeu/recs/contents.html. For CBECS see: http://www.eia.doe.gov/emeu/cbecs/contents.html.
} 
assumptions of the spreadsheet tools against EIA's data. Reference data are updated as newer versions of these documents are released and incorporated into EIA's version of NEMS.

\subsection{Penetration Rates}

As BEAMS relies heavily on assumptions about penetration rates, PNNL conducted a study to examine the historical market penetration (i.e., diffusion curves) for 10 energy-efficient products related to the buildings sector. ${ }^{8}$ PNNL estimated diffusion models for each product based on the specification proposed by F.M. Bass (1969). Bass was the first to suggest the S-curve or logistical functional form for the market diffusion of new products and his theories are still widely used today. PNNL incorporated these model diffusion curves into the analysis for several projects and technologies not modeled within NEMS. Technologies were placed into four categories: lighting; heating, ventilation, air-conditioning and refrigeration (HVAC/R); envelope; and "other;" and "like product" diffusion curves were assigned.

\subsection{Adjustments to Estimates Due to Budget Revisions}

The budget formulation process involves many iterations, and as such, the budget request may change substantially during that process. First, EERE develops an initial budget. Next, an internal review budget is developed in conjunction with the Chief Financial Officer. Eventually, the budget proceeds to the Office of Management and Budget (OMB) and subsequent versions are developed based on an appeal of the OMB pass back. Finally, the budget is formally submitted by the President to Congress (referred to in this document as the final budget request).

The project characterizations driving the benefits estimates are developed through close interaction with the BT and WIP project managers. The characterizations require the DOE manager to make assumptions based on the requested level of funding, and the characterization then describes what would be accomplished at that level. However, because the budget request sometimes changes between the time of initial characterization and when the budget request is finalized, a process needs to exist to quickly recalculate the estimated benefits for the various projects.

For small changes in budget levels, PNNL introduces a basic "budget adjustment" to the project estimates. We assume that to get to $\mathrm{X}$ savings, a total of $\mathrm{Y}$ budget must be spent, where $\mathrm{Y}$ is the cumulative budget over the projection period. A change in the annual budget results in a change in the cumulative budget. Revised savings are calculated for each year using the scaling factor: new cumulative budget in year $Z$ divided by old cumulative budget in year $Z$. This adjustment mechanism implicitly suggests that either the fraction of expected sales or the performance of the project has changed but does not explicitly tie the change to one factor or the other.

For larger changes, we revisit the project inputs and characterizations with the DOE managers to determine the impact of a reduced (or increased) budget. Common options for adjusting the models include changing the year of market introduction, changing the impact on sales (market penetration), modifying the performance objective, and adding or removing tasks or technologies within the project.

\footnotetext{
${ }^{8}$ See Section 3.0 in Elliott et al. 2004b.
} 


\subsection{Contents of this Document}

The remainder of this document consists of two sections. Section 2.0 provides detailed information on the methodology underlying the calculation of the benefits estimates using the BEAMS software. Section 3.0 lists the references for the document.

This document serves both as stand-alone documentation for BEAMS, and also as a supplemental update of a previous document, Methodological Framework for Analysis of Buildings-Related Programs: The GPRA Metrics Effort, (Elliott et al. 2004b). The areas most changed since publication of the previous document are those discussing the calculation of lighting and HVAC interactive effects (for both lighting and envelope/whole-building projects). This report does not attempt to convey inputs to BEAMS or the

methodology of their derivation. That information may be found in Baseline Inputs for BEAMS: Data Used in Preparing Methodological Framework for Analysis of Building-Related Programs: The GPRA Metrics Effort, June 2004 (Elliott et al. 2004a). 



\subsection{BEAMS Methodology}

This section describes the calculation methodology used within BEAMS to estimate the energy savings and associated outputs for buildings-related projects.

\subsection{Background Information on BEAMS}

BEAMS is a bottom-up accounting model that compares reference (or baseline) energy use against that of specific EERE-sponsored technologies. BEAMS is also used to centrally collect, store, and report all results produced by all of the various estimation methods (NEMS-PNNL and spreadsheets). In addition to energy savings forecasts, these results also include such items as associated emissions reductions and necessary capital investment.

BEAMS can estimate benefits for a number of project types: whole-building, envelope, lighting, HVAC, and water heating. BEAMS is used primarily to model projects that target whole-building energy use or envelope (building shell) improvements. Although BEAMS can model equipment projects, those projects are primarily estimated using NEMS-PNNL.

To determine energy savings for specific buildings-related projects, BEAMS requires information in the following areas:

- Project Performance Goals. The goals of each project are assessed in terms of energy savings (e.g., percent load reductions and equipment efficiency improvements) and used as inputs to BEAMS. PNNL gathers this information for each project by interviewing the Technology Development Manager (TDM) or reviewing project literature (e.g., technical reports, brochures, and websites).

- Target Market. Target markets are defined in terms of building sector (e.g., residential or commercial), building type (e.g., single family or educational), size (commercial only), income level (residential only), vintage (new or existing), and climate zone or region. Figure 2.1 illustrates the process used to define the project's targeted market segment within BEAMS, where certain building types and building sizes are excluded from the mix (indicated with arrow curving downward), leaving a more specific market to target.

Once the target market has been identified, PNNL determines penetration into that market using technology diffusion curves (discussed in Elliott et al. 2004b). Within BEAMS, market penetration is defined as either the fraction of sales for equipment and lighting projects or the fraction of installed base for envelope and whole-building projects. 


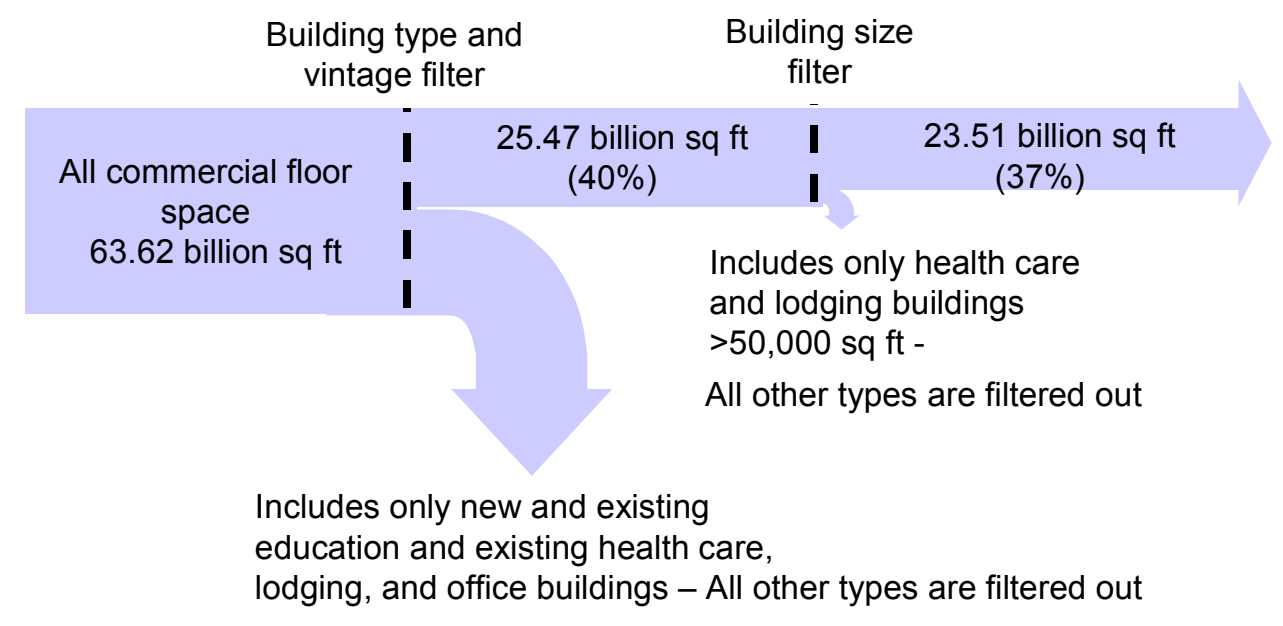

Penetration rates applied to market segment, used as input to BEAMS

Includes only health care and lodging buildings $>50,000 \mathrm{sq} f \mathrm{ft}$

All other types are filtered out

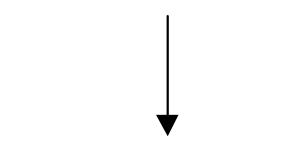

Benefits Estimates education and existing health care, lodging, and office buildings - All other types are filtered out

Figure 2.1. Developing the Market Segment (BEAMS)

- Private Investment (cost). Estimates of private investment for both the reference and the EERE technology or practice are entered into BEAMS. Ideally, the investment costs would be considered when market penetration is developed; however, the current diffusion model used does not incorporate costs at this time. In addition to private investment, non-energy project benefits are also quantified when possible and entered into BEAMS.

All site-level energy savings and investment estimates are aggregated through a BEAMS-toNEMS-PNNL interface. Project benefits estimated via spreadsheet are also entered into BEAMS. After this aggregation, BEAMS calculates the primary energy savings, associated emissions reductions, and dollar value of the energy savings. BEAMS contains a report generator that aggregates the project-level benefits into sub-programs. Each of the BEAMS algorithm approaches is further documented below.

\subsection{Whole-Building and Envelope Approach}

This section addresses projects that target the building envelope or use a whole-building design approach. Envelope projects are modeled as improvements to the building envelope (shell measures, such as improvements to wall insulation and windows), whereas whole-building projects impact the total building system. Envelope and whole-building projects are both characterized by a reduction in space conditioning and/or water heating load resulting from changes in the building system or envelope. Additionally, envelope and whole-building projects may also result in reductions in lighting load. Electrochromic windows are an example of a technology that may impact lighting consumption via a load reduction rather than via lighting technology efficiency improvements.

Calculating the energy savings associated with envelope and whole-building projects involves the following steps, which are discussed in the next subsections:

- Determine the size of the potential market.

- Determine the number of units affected by the buildings-related project.

- Determine the reference end-use loads.

- Determine the end-use loads after project implementation. 
- Calculate the energy savings.

- Calculate the heating and cooling interactive effects factors (if lighting loads are impacted).

- Calculate the change in space conditioning energy use due to interactive effects (if lighting loads are impacted).

- Derive the final energy savings (if lighting loads are impacted).

\subsubsection{Determine Size of the Potential Market}

Building stock estimates are used to determine the potential market for each project. The stock estimates are developed for each market segment (e.g., building sector, building type, building vintage, and region). Using the budget year as the base year, PNNL classifies all construction beginning with the base year as new.

Each envelope or whole-building project has a specified target market: residential and/or commercial (and their building-type subsets), new and/or existing vintages, and north and/or south regions. The potential market for any project is the set of targeted buildings. For example, a project targeting singlefamily construction includes only the forecasts for new and existing single-family construction in the north and south.

\subsubsection{Determine Number of Units Affected by the Buildings-Related Project}

The number of units affected by the buildings-related project is calculated using the fraction of installed base (penetration rate) that the project is expected to capture and the building stock. A penetration rate is applied to the appropriate market segment to compute the number of units impacted by the buildings-related project, as follows:

$$
u_{s, b, v, r, t}=P_{s, b, v, r, t} \times S_{s, b, v, r, t}
$$

Where $\quad \mathrm{u}_{\mathrm{s}, \mathrm{b}, \mathrm{v}, \mathrm{r}, \mathrm{t}} \quad=$ number of units affected in year $t$ (billion $\mathrm{ft}^{2}$ or million households) for building sector $s$, building type $b$, vintage $v$, and region $r$

$\mathrm{P}_{\mathrm{s}, \mathrm{b}, \mathrm{v}, \mathrm{r}, \mathrm{t}}=$ penetration rate in year $t$ for building sector $s$, building type $b$, vintage $v$, and region $r$

$\mathrm{S}_{\mathrm{s}, \mathrm{b}, \mathrm{v}, \mathrm{r}, \mathrm{t}}=$ building stock in year $t$ (billion $\mathrm{ft}^{2}$ or million households) for building sector $s$, building type $b$, vintage $v$, and region $r$.

All equations in the BEAMS methodology are broken out by building sector, type, vintage, and region. To keep the subsequent equations readable, the subscripts for these categorizations are omitted.

For new building stock, which represents annual construction, the product in Equation 2-1 provides the number of impacted units in year $t$. However, for existing buildings, this calculation actually yields a cumulative number, as represented below in Equation 2-2:

$$
U_{t}=\sum_{i=1}^{t} u_{i} \times \frac{S_{t}}{S_{i}}
$$




Where $\quad \begin{array}{ll}\mathrm{U}_{\mathrm{t}} & =\begin{array}{l}\text { cumulative surviving units impacted through year } t \text { (billion } \mathrm{ft}^{2} \text { or million } \\ \text { households) }\end{array} \\ & =\text { number of units impacted in year } i \text { (billion } \mathrm{ft}^{2} \text { or million households) } \\ \mathrm{u}_{\mathrm{i}} & =\text { building stock in year } t \text { (billion } \mathrm{ft}^{2} \text { or million households) } \\ \mathrm{S}_{\mathrm{t}} & =\text { building stock in year } i \text { (billion } \mathrm{ft}^{2} \text { or million households). }\end{array}$

Within BEAMS, the existing building stock is defined as the total stock at the beginning of the base year, which subsequently gradually declines over time through events such as fires and demolition. The total units affected at time $t$ for existing buildings are, in effect, cumulative to that time period because penetration occurs against that same entire (although gradually declining) stock each year. As a result, the number of existing-vintage installed units by year must be disaggregated, while also accounting for the effects of declining building stock on units from previous years. In other words, only the incremental units affected in a given year should be captured, and this additional step ensures that that occurs. Equation 2-3 explicitly shows this step that addresses the problem of cumulative units for existing-vintage buildings:

$$
u_{t}=U_{t}-\left(U_{t-1} \times \frac{S_{t}}{S_{t-1}}\right) \text { for } \mathrm{t}>1
$$

\subsubsection{Determine Reference End-Use Loads}

End-use loads represent the reference service requirements per square foot (commercial) or per household (residential) for heating, cooling, water heating, and lighting. The units for commercial building loads are $\mathrm{kBtu} / \mathrm{ft}^{2}$, or in the case of lighting, thousand lumen-hours $/ \mathrm{ft}^{2}$. For residential buildings the corresponding units are MMBtu/household and million lumen-hours/household. Reference end-use loads are distinguished by building types (e.g., assembly, education, multifamily) as well as by vintage and regions (derived from climate zones).

The performance improvements for envelope and whole-building projects are characterized by reductions in the end-use loads. Therefore, the reference energy consumption does not have to be explicitly calculated. Instead, the load reduction is applied to the reference load to determine the new load, and the resulting difference in loads is used to calculate energy savings.

\subsubsection{Determine End-Use Loads After Project Implementation}

The performance inputs for envelope and whole-building projects are defined in terms of percent load reductions. A given project may impact multiple end uses with end-use specific load reductions. The load reductions are applied to the corresponding end-use load segments to determine the building-level load reductions by end use, as follows:

$$
l r_{e, t}=L_{e, t} \times R_{e, t}
$$

Where $\quad \mathrm{rr}_{\mathrm{e}, \mathrm{t}}=$ building-level load reduction (in $\mathrm{kBtu} / \mathrm{ft}^{2}$ or MMBtu/household, or in the case of lighting, thousand lumen-hours/ $\mathrm{ft}^{2}$ or million lumen-hours/household) in year $t$ for end-use $e$ 


$$
\begin{aligned}
\mathrm{L}_{\mathrm{e}, \mathrm{t}}= & \text { load in year } t\left(\mathrm{kBtu} / \mathrm{ft}^{2}, \mathrm{MMBtu} / \text { household, thousand lumen-hours } / \mathrm{ft}^{2},\right. \text { or million } \\
& \text { lumen-hours/household) for end-use } e \\
\mathrm{R}_{\mathrm{e}, \mathrm{t}}= & \text { percent load reduction in year } t \text { for end-use } e .
\end{aligned}
$$

The building-level load reductions are translated into aggregate load reductions by region as follows:

$$
L R_{e, t}=l r_{e, t} \times u_{t}
$$

Where $\quad \mathrm{LR}_{\mathrm{e}, \mathrm{t}} \quad=$ regional load reduction in year $t$ for end-use $e$ (TBtu, or for lighting, trillion lumen-hours)

$\mathrm{lr}_{\mathrm{e}, \mathrm{t}}=$ building-level load reduction in year $t$ for end-use $e\left(\mathrm{kBtu} / \mathrm{ft}^{2}, \mathrm{MMBtu} /\right.$ household, thousand lumen-hours/ $\mathrm{ft}^{2}$, or million lumen-hours/household)

$\mathrm{u}_{\mathrm{t}} \quad=$ total number of units impacted in year $t$ (calculated in Equation 2-3 [existing] or Equation 2-1 [new], (billion $\mathrm{ft}^{2}$ or million households)).

At this point, these potential load reductions are cumulated across years of the analysis. Each installation under the project continues to have savings impacts beyond the initial year of installation. The calculations, as shown in the equations below, provide aggregate load reductions in each year, while taking into account the effect of declining building stock for existing buildings. This declining building stock acts to reduce savings somewhat over time. For existing buildings:

$$
C L R_{e, t}=\sum_{i=1}^{t} L R_{e, i} \times \frac{S_{t}}{S_{i}}
$$

Where $\quad \mathrm{CLR}_{\mathrm{e}, \mathrm{t}} \quad=$ cumulative regional load reduction in year $t$ for end-use $e$ (TBtu or trillion lumenhours)

$\mathrm{LR}_{\mathrm{e}, \mathrm{i}}=$ regional load reduction in year $i$ for end-use $e$ (TBtu or trillion lumen-hours)

$\mathrm{S}_{\mathrm{t}} \quad=$ building stock in year $t$ (billion $\mathrm{ft}^{2}$ or million households)

$\mathrm{S}_{\mathrm{i}} \quad=$ building stock in year $i$ (billion $\mathrm{ft}^{2}$ or million households).

For new buildings:

$$
C L R_{e, t}=\sum_{i=1}^{t} L R_{e, i}
$$

Where $\quad \mathrm{CLR}_{\mathrm{e}, \mathrm{t}} \quad=$ cumulative regional load reduction in year $t$ for end-use $e$ (TBtu or trillion lumenhours)

$\mathrm{LR}_{\mathrm{e}, \mathrm{i}}=$ regional load reduction in year $i$ for end-use $e$ (TBtu or trillion lumen-hours).

\subsubsection{Calculate Energy Savings}

The cumulative regional load reductions must be translated into regional energy savings, requiring reference-case assumptions for existing equipment efficiencies and existing equipment market shares, which are broken out by market segment.

First, the cumulative regional load reductions are divided by the reference equipment efficiencies, yielding potential energy savings by equipment type and end use. For envelope projects, this efficiency is 
the stock efficiency, or the efficiency of the existing installed base of equipment. Envelope projects do not replace any existing pieces of equipment, impacting only the building shell. In contrast, wholebuilding projects completely renovate a building and would likely include newly replaced or installed equipment. Sales or current-year equipment efficiencies are used in this case. It is this distinction that differentiates the envelope and whole-building variations of this algorithm. The potential energy savings assume that each equipment type has $100 \%$ of the market, so the actual equipment market shares must then be applied. The market share for each equipment type is multiplied by the potential energy savings to determine the actual energy savings. Equation 2-8 illustrates the energy savings by equipment type and end use calculations:

$$
C E S_{e, f, q, t}=\frac{C L R_{e, t}}{e_{e, f, q, t}} \times M_{e, f, q, t}
$$

Where $\quad \mathrm{CES}_{\mathrm{e}, \mathrm{f}, \mathrm{q}, \mathrm{t}}=$ cumulative regional energy savings in year $t$ for end-use $e$, fuel type $f$, and equipment type $q$ (TBtu, or for lighting, billion $\mathrm{kWh}$ )

$\mathrm{CLR}_{\mathrm{e}, \mathrm{t}}=$ cumulative regional load reduction in year $t$ for end-use $e$ (TBtu or trillion lumenhours)

$\mathrm{e}_{\mathrm{e}, \mathrm{f}, \mathrm{q}, \mathrm{t}}=$ reference equipment efficiency in year $t$ for end-use $e$, fuel type $f$, and equipment type $q$ (for lighting, this is lumens/watt, for other equipment this may be in terms of AFUE, COP, SCOP, or EF)

$\mathrm{M}_{\mathrm{e}, \mathrm{f}, \mathrm{q}, \mathrm{t}}=$ market share in year $t$ for end-use $e$, fuel type $f$, and equipment type $q$.

After converting lighting savings to TBtu, lighting interactions with heating and cooling are examined, as described in the following sections. In the absence of lighting savings (and hence the need to examine interactive effects), all calculated savings are aggregated by building sector, type, vintage, region, end use, and fuel type to determine the total site electric savings, total natural gas savings, and total oil savings.

\subsubsection{Calculate Heating and Cooling Interactive Effects Factors}

A change in lighting consumption significantly impacts other end uses as well, due to the fact that lights produce heat. As more efficient lighting or lighting load reductions are incorporated in buildings, heating loads can be expected to increase, while cooling loads should be reduced. These interactions are accounted for through the development and use of lighting interaction factors. BEAMS incorporates interactive effects coefficients as inputs, which are used to derive heating and cooling load change factors.

\subsubsection{Derivation of the Interactive Effects Coefficients-Reference}

Reference loads were determined using NEMSFEDS, an iteration tool based on FEDS that allows a single case to be modified and run (loads only) by altering inputs to a [casename].ini file. In this manner a single case can be used to run a multi-dimensional matrix of all combinations of building type, size, vintage, location, occupancy, and lighting configurations. Statistical data of actual building size and vintage information were then used to combine the NEMSFEDS results into a location by building type results matrix where each building type is of the weighted average size and weighted average vintage (for existing) or 2000 vintage for new buildings. 
Values were determined for all combinations of the following:

- commercial, residential, and industrial building types

- new and existing buildings

- nine census regions (and north and south for BEAMS).

\subsubsection{Derivation of the Interactive Effects Coefficients-Variation from Reference}

Lighting consumption was decreased from $100 \%$ to $0 \%$ with $10 \%$ steps. As a result of the decrease in lighting consumption, the heating load increased and the cooling load decreased. The fractional increases in the heating load and fractional decreases in the cooling load were then determined at each of the steps. Lastly, the results were converted via regression to equations (one for heating and one for cooling for each combination of building type, new/existing, and location) where the only input is the lighting consumption reduction percentage. The regression equations are of the form:

$$
\begin{aligned}
& \text { sheat }=a \times \Delta L^{b} \\
& \Delta \text { cool }=c \times \Delta L^{2}+d \times \Delta L
\end{aligned}
$$

Where $a, b, c$, and $d$ are the interactive effects coefficients

$$
\begin{aligned}
& \Delta \text { heat }=\text { the fractional change in heating load } \\
& \Delta \text { cool }=\text { the fractional change in cooling load } \\
& \Delta \mathrm{L}=\text { the lighting consumption reduction percentage. }
\end{aligned}
$$

\subsubsection{Specification of the Lighting Consumption Reduction Percentage}

The lighting consumption reduction percentage is defined as the percentage of the total lighting electricity consumption that is reduced across all lighting technologies. In the case of projects that reduce lighting load, the formulation is simple: the lighting consumption reduction percentage is equal to the lighting load reduction percentage, which affects all lighting technologies. This lighting consumption reduction percentage $(\Delta \mathrm{L})$ is input into the $\Delta$ heat and $\Delta$ cool equations, yielding the heating and cooling interactive effects factors.

\subsubsection{Calculation of Interactive Effects Factors}

Taking the general formulation provided in the section above and applying it to the specific case of envelope and whole-building projects in BEAMS, the lighting consumption reduction percentage is calculated as:

$$
\Delta L_{t}=R_{t}
$$

Where $\Delta \mathrm{L}_{\mathrm{t}} \quad=$ the lighting consumption reduction percentage in year $t$

$\mathrm{R}_{\mathrm{t}}=$ the lighting load reduction percentage in year $t$.

Note that while load reductions are also broken out by end use within BEAMS, in this particular case only lighting is relevant. 
At this point, the required components for calculating the interactive effects factors are available. Using Equations 2-9 and 2-10, year-specific factors $\Delta$ heat $t_{t}$ and $\Delta$ cool $_{t}$ are computed. During these calculations, a constraint is placed on $\Delta$ cool $_{t}$. While it is theoretically possible for a heating load to increase by more than $100 \%$ as a result of a lighting efficiency project, it is not possible to eliminate more than an entire cooling load. As a result, if $\Delta \mathrm{cool}_{\mathrm{t}}<-1$, it is set to -1 .

\subsubsection{Calculate Change in Space Conditioning Energy Use Due to Interactive Effects}

The first step necessary to derive actual space conditioning energy impacts via the use of the interactive effects factors is to consider an appropriate measure of impacted units (billion $\mathrm{ft}^{2}$ or million households). In the case of envelope and whole-building projects, the HVAC interactive effects impact the same area as the lighting load reductions. As a result, the number of units affected is:

$$
I u_{t}=u_{t}
$$
Where $\quad \mathrm{Iu}_{\mathrm{t}} \quad=$ number of units affected by interactive effects in year $t$ (billion $\mathrm{ft}^{2}$ or million households)
$\mathrm{u}_{\mathrm{t}} \quad=$ number of units impacted by load reduction project in year $t$ (billion $\mathrm{ft}^{2}$ or million households).

The load changes from interactive effects are calculated by applying the interactive effects factors to the net loads remaining after any direct heating and cooling impacts of the load reduction projects, as calculated previously with equation 2-4. As noted earlier, as lighting efficiency increases, cooling loads decrease and heating loads increase. As a result, the calculated values for $\Delta$ heat are positive, and those for $\Delta$ cool are negative. Because the load reduction, rather than the change in load, is the desired output, a sign change is applied in the following calculation:

For heating:

$$
I l r_{e, t}=\left(L_{e, t}-l r_{e, t}\right) \times\left(-\Delta h e a t_{t}\right)
$$

For cooling:

$$
I l r_{e, t}=\left(L_{e, t}-l r_{e, t}\right) \times\left(-\Delta \operatorname{cool}_{t}\right)
$$

Where $\quad \operatorname{Ilr}_{\mathrm{e}, \mathrm{t}}=$ building-level load reduction in year $t$ for end-use $e$, due to interactive effects (kBtu/ $\mathrm{ft}^{2}$ or MMBtu/household)

$\mathrm{L}_{\mathrm{e}, \mathrm{t}} \quad=$ load in year $\mathrm{t}$ for end-use $e\left(\mathrm{kBtu} / \mathrm{ft}^{2}\right.$ or MMBtu/household $)$

$\mathrm{rr}_{\mathrm{e}, \mathrm{t}} \quad=$ building-level load reduction in year $\mathrm{t}$ for end-use $e$, due to direct impacts of load reduction project $\left(\mathrm{kBtu} / \mathrm{ft}^{2}\right.$ or MMBtu/household)

$\Delta$ heat $_{\mathrm{t}}=$ the fractional change in heating load (or the heating interactive effects factor) in year $t$

$\Delta$ cool $_{t}=$ the fractional change in cooling load (or the cooling interactive effects factor) in year $t$. 
The building-level load reductions are translated into regional load reductions as follows:

$$
I L R_{e, t}=I l r_{e, t} \times I u_{t}
$$

Where $\quad \mathrm{ILR}_{\mathrm{e}, \mathrm{t}}=$ regional load reduction in year $t$ for end-use $e$, due to interactive effects (TBtu)

$\mathrm{Ilr}_{\mathrm{e}, \mathrm{t}}=$ building-level load reductions in year $t$ for end-use $e$, due to interactive effects $\left(\mathrm{kBtu} / \mathrm{ft}^{2}\right.$ or MMBtu/household)

$\mathrm{Iu}_{\mathrm{t}} \quad=$ number of units affected by interactive effects in year $t$ (billion $\mathrm{ft}^{2}$ or million households).

At this point, the load reductions are cumulated across years of the analysis. Each installation under the project continues to provide savings impacts beyond the initial year of installation, and with those continued savings come load reductions due to interactive effects. Therefore, in a given year, such load reductions may result from installations in several previous years as well. The calculations, as shown in the equations below, provide aggregate load reductions in each year, while taking into account the effect of declining building stock for existing buildings. This declining building stock acts to reduce the load reductions somewhat over time. For existing buildings:

$$
C I L R_{e, t}=\sum_{i=1}^{t} I L R_{e, i} \times \frac{S_{t}}{S_{i}}
$$

Where $\quad$ CILR $_{\mathrm{e}, \mathrm{t}}=$ cumulative regional load reduction in year $t$ for end-use $e$, due to interactive effects (TBtu)

$\mathrm{ILR}_{\mathrm{e}, \mathrm{i}}=$ regional load reduction in year $i$ for end-use $e$, due to interactive effects (TBtu)

$\mathrm{S}_{\mathrm{t}} \quad=$ building stock in year $t$ (billion $\mathrm{ft}^{2}$ or million households)

$\mathrm{S}_{\mathrm{i}} \quad=$ building stock in year $i$ (billion $\mathrm{ft}^{2}$ or million households).

For new buildings:

$$
C I L R_{e, t}=\sum_{i=1}^{t} I L R_{e, i}
$$

Where $\quad$ ILR $_{\mathrm{e}, \mathrm{t}}=$ cumulative regional load reduction in year $t$ for end-use $e$, due to interactive effects (TBtu)

$\mathrm{ILR}_{\mathrm{e}, \mathrm{i}}=$ regional load reduction in year $i$ for end-use $e$, due to interactive effects (TBtu).

Earlier a constraint was placed on $\Delta \mathrm{cool}_{t}$, to eliminate the unreasonable outcome of eliminating more than an entire cooling load due to interactive effects. At this point it is necessary to implement a reality check on both heating and cooling, as the magnitude of the heating and cooling load changes can not exceed the magnitude of the aggregated-to-end-use level lighting consumption change, derived from the results calculated earlier in equation 2-8.

For heating:

$$
\text { If }\left|\mathrm{CES}_{\text {light } \mathrm{t}}\right|<\left|\operatorname{CILR}_{e, t}\right| \text { then } \operatorname{CILR}_{e, t}=-\mathrm{CES}_{\text {light }, \mathrm{t}}
$$


For cooling:

$$
\text { If }\left|\mathrm{CES}_{\text {light }, \mathrm{t}}\right|<\left|\operatorname{CILR}_{e, t}\right| \text { then } \operatorname{CILR}_{e, t}=\mathrm{CES}_{\text {light }, \mathrm{t}}
$$

Where $\quad \mathrm{CES}_{\text {light, }}=$ cumulative regional energy savings in year $t$ for lighting (TBtu)

$\mathrm{CILR}_{\mathrm{e}, \mathrm{t}}=$ cumulative regional load reductions in year $t$ for end-use $e$, due to interactive effects (TBtu).

These load reductions must be translated into energy savings. To do this, reference assumptions regarding existing equipment efficiencies and existing equipment market shares are used. First, the load reductions resulting from interactive effects are divided by the reference (existing) equipment efficiencies, which yields potential energy savings by equipment type, end use, and fuel type. For envelope projects, these efficiencies are stock efficiencies, or the efficiencies of the existing installed base of equipment. Envelope projects do not replace any existing pieces of equipment, impacting only the building shell. In contrast, whole-building projects completely renovate a building and would likely include newly replaced or installed equipment. Sales, or current-year, equipment efficiencies are used in this case. (In the case of new buildings, stock and sales efficiencies are identical in BEAMS). The potential energy savings assume that each equipment type has $100 \%$ of the market, so the actual equipment market shares must now be applied. The market share for each equipment type is multiplied by the potential energy savings to determine the actual energy savings. Equation 2-20 illustrates the calculations:

$$
I E S_{e, f, q, t}=\frac{C I L R_{e, t}}{e_{e, f, q, t}} \times M_{e, f, q, t}
$$

Where $\quad \mathrm{IES}_{\mathrm{e}, \mathrm{f}, \mathrm{q}, \mathrm{t}}=$ energy savings in year $t$ due to interactive effects for end-use $e$, fuel type $f$, and equipment type $q$ (TBtu)

$\mathrm{CILR}_{\mathrm{e}, \mathrm{t}}=$ cumulative regional load reductions in year $t$ due to interactive effects for end-use $e$ (TBtu)

$\mathrm{e}_{\mathrm{e}, \mathrm{f}, \mathrm{q}, \mathrm{t}}=$ reference equipment efficiency in year $t$ for end-use $e$, fuel type $f$, and equipment type $q$ (AFUE, COP, or SCOP)

$\mathrm{M}_{\mathrm{e}, \mathrm{f}, \mathrm{q}, \mathrm{t}}=$ equipment market share in year $t$ for end-use $e$, fuel type $f$, and equipment type $q$.

\subsubsection{Derive Final Energy Savings}

The lighting energy savings and the space-conditioning energy savings are combined and summed over equipment types to provide the final net energy savings by end use. The final net energy savings are aggregated by building sector, type, vintage, region, end use, and fuel type to determine the total site electric savings, total natural gas savings, and total oil savings.

\subsection{Equipment Approach}

This section addresses projects that target equipment other than lighting. Equipment projects are characterized by changes in equipment efficiency. 
Calculating the energy savings associated with an equipment project involves the following steps, which are discussed in the next subsections:

- Determine the size of the potential market and the number of units affected by the buildings-related project.

- Calculate adjustments to the potential market and units affected.

- Determine the reference energy consumption of impacted units.

- Determine the energy consumption of impacted units after project implementation.

- Calculate the energy savings.

\subsubsection{Determine Size of Potential Market and Number of Units Affected by the Buildings-Related Project}

Estimates of building stock, reference equipment market share and life, project equipment life, and penetration rates all play a role in determining the potential market and the number of units affected by equipment projects. Unlike the relatively straightforward calculations for envelope and whole-building, equipment calculations are much more complicated. The primary driver behind this is the fact that equipment projects involve devices that fail within a shorter time-frame, relative to the envelope and whole-building projects, and must be replaced during the analysis period. Despite the additional level of complexity, the initial steps are similar.

Each equipment project has a specified target market: residential and/or commercial (and their subsets), new and/or existing vintages, and north and/or south regions.

For the initial calculation, the potential market for any equipment project is, for the targeted building set, the product of the equipment stock and the reference equipment replacement factor. The equipment stock is derived through multiplication of the building stock and the equipment market shares. A replacement factor is calculated as the inverse of reference equipment life, and indicates the frequency of required replacements. As indicated by the lack of a time subscript, $t$, equipment life and the associated replacement factor may not vary over the analysis period for a given end use, fuel type, and equipment type combination. The derivations of equipment stock and the potential market are shown in Equations 221 and 2-22, respectively.

$$
S E_{e, f, q, t}=S_{t} \times M_{e, f, q, t}
$$

Where $\quad \mathrm{SE}_{\mathrm{e}, \mathrm{f}, \mathrm{q}, \mathrm{t}}=$ equipment stock in year $t$ for end-use $e$, fuel type $f$, and equipment type $q$ (billion $\mathrm{ft}^{2}$ or million households)

$\mathrm{S}_{\mathrm{t}} \quad=$ building stock in year $t$ (billion $\mathrm{ft}^{2}$ or million households)

$\mathrm{M}_{\mathrm{e}, \mathrm{f}, \mathrm{q}, \mathrm{t}}=$ equipment market share in year $t$ for end-use $e$, fuel type $f$, and equipment type $q$.

$$
P M_{e, f, q, t}=S E_{e, f, q, t} \times \frac{1}{\operatorname{RLife}_{e, f, q}}=S E_{e, f, q, t} \times R R_{e, f, q}
$$

Where $\quad \mathrm{PM}_{\mathrm{e}, \mathrm{f}, \mathrm{q}, \mathrm{t}}=$ potential market in year $t$ for end-use $e$, fuel type $f$, and equipment type $q$ (billion $\mathrm{ft}^{2}$ or million households) 


$$
\begin{aligned}
\mathrm{SE}_{\mathrm{e}, \mathrm{f}, \mathrm{q}, \mathrm{t}}= & \text { equipment stock in year } t \text { for end-use } e \text {, fuel type } f \text {, and equipment type } q \text { (billion } \\
& \mathrm{ft}^{2} \text { or million households) } \\
\mathrm{RLife}_{\mathrm{e}, \mathrm{f}, \mathrm{q}}= & \text { reference equipment life expectancy for end-use } e \text {, fuel type } f \text {, and equipment type } \\
& q \text { (years) } \\
\mathrm{RR}_{\mathrm{e}, \mathrm{f}, \mathrm{q}}= & \text { reference equipment replacement factor for end-use } e \text {, fuel type } f \text {, and equipment } \\
& \text { type } q .
\end{aligned}
$$

To initially calculate the number of units affected by the buildings-related project, the penetration rate, or fraction of sales, is applied to the potential market, as follows:

$$
u_{e, f, q, n f, t}=P_{e, f, q, n f, t} \times P M_{e, f, q, t}
$$

Where $\quad \mathrm{u}_{\mathrm{e}, \mathrm{f}, \mathrm{q}, \mathrm{nf}, \mathrm{t}}=$ number of units affected in year $t$ for end-use $e$, existing fuel type $f$, equipment type $q$, and new fuel $n f$ (billion $\mathrm{ft}^{2}$ or million households)

$\mathrm{P}_{\mathrm{e}, \mathrm{f}, \mathrm{q}, \mathrm{nf}, \mathrm{t}}=$ penetration rate in year $t$ for end-use $e$, existing fuel type $f$, equipment type $q$, and new fuel $n f$

$\mathrm{PM}_{\mathrm{e}, \mathrm{f}, \mathrm{q}, \mathrm{t}}=$ potential market in year $t$ for end-use $e$, fuel type $f$, and equipment type $q$ (billion $\mathrm{ft}^{2}$ or million households).

In reality, $f$ sufficiently represents the various possible fuel types. However, to illuminate the significant probability of fuel switching under equipment projects, $n f$ is used here to represent the fuel type of project-installed equipment. Where there is no fuel switching, $n f=f$.

In contrast to the case for envelope and whole-building projects, the basic units calculation for equipment illustrated here does not require any special handling of existing buildings. With envelope and whole-building projects, penetration occurs against the entire building stock. For equipment projects, penetration occurs against only a portion of the building stock because of the use of a replacement factor. As a result, the existing-vintage cumulative problem described in the envelope and whole-building approach does not exist here. As noted in Section 1.2, BEAMS, absent case-specific development of custom algorithm components, cannot model equipment that competes against more than one reference equipment type (e.g., heat pumps for heating and air-conditioning competing against both a gas furnace and an electric air conditioner).

\subsubsection{Calculate Adjustments to Potential Market and Units Affected}

While this initial calculation of potential market and impacted units outlined above is fairly simple, the following steps are much more involved. Because reference equipment life and project equipment life may differ, a project installation (unit impacted) in year $t$ may impact the potential market in future years, which in turn affects project installations in future years. Handling this issue requires an iterative process. The results of the calculations of the previous section serve as inputs to this process.

The issue of differing reference and project-sponsored equipment lives is not the only complicating factor. The annual (rather than cumulative) nature of new building stock numbers requires unique coding to ensure recompetition of new-vintage installations upon equipment failure. This treatment renders newvintage handling consistent with that for existing buildings. Without this added treatment, new-vintage installations (whether reference equipment or project equipment) would always be replaced with like equipment upon failure, ignoring a valid possibility of additional penetration of the advanced technology. 
Beginning with the existing-vintage case for the potential market, the calculations of this iterative updating process are outlined below as a series of conditional statements:

$$
\begin{aligned}
& P M_{e, f, q, t}= \\
& \left(\text { If }(t-1) \geq \text { RLife }_{e, f, q} \text { then } \frac{P M_{e, f, q,\left(t-R L i f e_{e, f, q}\right)}}{S E_{e, f, q,\left(t-R L i f e_{e, f, q}\right)}} \times S E_{e, f, q, t}, \text { else PM } M_{e, f, q, t}\right) \\
& -\left(\text { If }(t-1) \geq \text { RLife }_{e, f, q} \text { then } \frac{u_{e, f, q, n f,\left(t-R L i e_{e, f, q}\right)}}{S E_{e, f, q,\left(t-\text { RLife }_{e, f, q}\right)}} \times S E_{e, f, q, t}, \text { else } 0\right) \\
& +\left(\text { If }(t-1) \geq \text { PLife }_{e, f, q} \text { then } \frac{u_{e, f, q, n f,\left(t-P L i f e_{e, f, q}\right)}}{S E_{e, f, q,\left(t-P L i f e_{e, f, q}\right)}} \times S E_{e, f, q, t}, \text { else } 0\right)
\end{aligned}
$$

Where $\quad \mathrm{PM}_{\mathrm{e}, \mathrm{f}, \mathrm{q}, \mathrm{t}}=$ potential market in year $t$ for end-use $e$, fuel type $f$, and equipment type $q$ (billion $\mathrm{ft}^{2}$ or million households)

RLife $_{\mathrm{e}, \mathrm{f}, \mathrm{q}}=$ reference equipment life expectancy for end-use $e$, fuel type $f$, and equipment type $q$ (years)

PLife $_{\mathrm{e}, \mathrm{f}, \mathrm{q}}=$ project equipment life expectancy for end-use $e$, fuel type $f$, and equipment type $q$ (years)

$\mathrm{SE}_{\mathrm{e}, \mathrm{f}, \mathrm{q}, \mathrm{t}}=$ equipment stock in year $t$ for end-use $e$, fuel type $f$, and equipment type $q$ (billion $\mathrm{ft}^{2}$ or million households)

$\mathrm{u}_{\mathrm{e}, \mathrm{f}, \mathrm{q}, \mathrm{nf}, \mathrm{t}}=$ number of units affected in year $t$ for end-use $e$, existing fuel type $f$, equipment type $q$, and new fuel $n f$ (billion $\mathrm{ft}^{2}$ or million households).

For new buildings:

$$
\begin{aligned}
& P M_{e, f, q, t}=\left(S E_{e, f, q, t}\right)+\left(\operatorname{If}(t-1) \geq \text { RLife }_{e, f, q} \text { then } P M_{e, f, q,\left(t-R L i f e_{e, f, q}\right)} \times\left(1-P_{e, f, q, n f,\left(t-R L i f e_{e, f, q}\right.}\right), \text { else } 0\right) \\
& +\left(\text { If }(t-1) \geq \text { PLife }_{e, f, q} \text { then } u_{e, f, q, n f,\left(t-P L i f e_{e, f, q}\right.}, \text { else } 0\right)
\end{aligned}
$$

Where $\quad \mathrm{PM}_{\mathrm{e}, \mathrm{f}, \mathrm{q}, \mathrm{t}}=$ potential market in year $t$ for end-use $e$, fuel type $f$, and equipment type $q$ (billion $\mathrm{ft}^{2}$ or million households)

RLife $_{\mathrm{e}, \mathrm{f}, \mathrm{q}}=$ reference equipment life expectancy for end-use $e$, fuel type $f$, and equipment type $q$ (years)

PLife $_{\mathrm{e}, \mathrm{f}, \mathrm{q}}=$ project equipment life expectancy for end-use $e$, fuel type $f$, and equipment type $q$ (years)

$\mathrm{SE}_{\mathrm{e}, \mathrm{f}, \mathrm{q}, \mathrm{t}}=$ equipment stock in year $t$ for end-use $e$, fuel type $f$, and equipment type $q$ (billion $\mathrm{ft}^{2}$ or million households)

$\mathrm{P}_{\mathrm{e}, \mathrm{f}, \mathrm{q}, \mathrm{nf}, \mathrm{t}}=$ penetration rate in year $t$ for end-use $e$, existing fuel type $f$, equipment type $q$, and new fuel $n f$

$\mathrm{u}_{\mathrm{e}, \mathrm{f}, \mathrm{q}, \mathrm{nf}, \mathrm{t}}=$ number of units affected in year $t$ for end-use $e$, existing fuel type $f$, equipment type $q$, and new fuel $n f$ (billion $\mathrm{ft}^{2}$ or million households). 
These calculations are carried out for all years sequentially for each market segment, beginning with the first year. After the potential market is recalculated for a given year, the impacted units for that year must be recalculated, using Equation 2-23.

\subsubsection{Determine Reference Energy Consumption of Impacted Units}

Building-level reference energy consumption is calculated by dividing end-use loads by reference equipment efficiencies. These efficiencies represent the sales, or current-year, efficiencies of equipment that would be installed absent a buildings-related project. End-use loads represent the reference service requirements per square foot (commercial) or per household (residential) for heating, cooling, and water heating. As such, they must be divided by an efficiency to determine energy consumption:

$$
r c_{e, f, q, t}=\frac{L_{e, t}}{e_{e, f, q, t}}
$$

Where $\quad \mathrm{rc}_{\mathrm{e}, \mathrm{f}, \mathrm{q}, \mathrm{t}}=$ building-level reference consumption in year $t$ for end-use $e$, fuel type $f$, and equipment type $q\left(\mathrm{kBtu} / \mathrm{ft}^{2}\right.$ or MMBtu/household $)$

$\mathrm{L}_{\mathrm{e}, \mathrm{t}} \quad=$ end-use load in year $t$ for end-use $e\left(\mathrm{kBtu} / \mathrm{ft}^{2}\right.$ or MMBtu/household $)$

$\mathrm{e}_{\mathrm{e}, \mathrm{f}, \mathrm{q}, \mathrm{t}}=$ reference equipment efficiency in year $t$ for end-use $e$, fuel type $f$, and equipment type $q$ (AFUE, COP, SCOP, or EF).

Multiplying this result by the number of impacted units yields regional reference consumption:

$$
R C_{e, f, q, t}=r c_{e, f, q, t} \times u_{e, f, q, t}
$$

Where $\quad \mathrm{RC}_{\mathrm{e}, \mathrm{f}, \mathrm{q}, \mathrm{t}}=$ regional reference consumption of impacted units in year $t$ for end-use $e$, fuel type $f$, and equipment type $q$ (TBtu)

$\mathrm{rc}_{\mathrm{e}, \mathrm{f}, \mathrm{q}, \mathrm{t}}=$ building-level reference consumption in year $t$ for end-use $e$, fuel type $f$, and equipment type $q\left(\mathrm{kBtu} / \mathrm{ft}^{2}\right.$ or MMBtu/household)

$\mathrm{u}_{\mathrm{e}, \mathrm{f}, \mathrm{q}, \mathrm{t}}=$ total number of units impacted in year $t$ for end-use $e$, fuel type $f$, and equipment type $q$ (billion $\mathrm{ft}^{2}$ or million households).

Because the final goal is calculating energy savings associated with impacted units, deriving total reference consumption is not necessary; rather reference consumption associated with impacted units only suffices.

At this point, the consumption figures are cumulated across years of the analysis. Each piece of equipment continues to consume energy throughout its lifetime. Therefore, in a given year, consumption may result from equipment installed in several previous years as well. The calculations, as shown in the equations below, provide aggregate energy consumption in each year, while taking into account the effect of declining building stock for existing buildings. This declining building stock acts to reduce consumption somewhat over time. To compare the reference and project equipment's energy usage appropriately, the reference consumption is cumulated over the lifetime of the project equipment. For existing buildings: 


$$
\begin{aligned}
& C R C_{e, f, q, t}=\sum_{i=\left(t-P L i f f_{e, f, q}\right)}^{t} R C_{e, f, q, i} \times \frac{S_{t}}{S_{i}}, \text { for } \mathrm{t}>\text { PLife } \\
& C R C_{e, f, q, t}=\sum_{i=1}^{t} R C_{e, f, q, i} \times \frac{S_{t}}{S_{i}}, \text { for } \mathrm{t} \leq \text { PLife }
\end{aligned}
$$

Where $\quad \mathrm{CRC}_{\mathrm{e}, \mathrm{f}, \mathrm{q}, \mathrm{t}}=$ cumulative regional reference energy consumption in year $t$ for end-use $e$, fuel type $f$, and equipment type $q$ (TBtu)

$\mathrm{RC}_{\mathrm{e}, \mathrm{f}, \mathrm{q}, \mathrm{i}}=$ regional reference energy consumption in year $i$ for end-use $e$, fuel type $f$, and equipment type $q$ (TBtu)

$\mathrm{S}_{\mathrm{t}} \quad=$ building stock in year $t$ (billion $\mathrm{ft}^{2}$ or million households)

$\mathrm{S}_{\mathrm{i}} \quad=$ building stock in year $i$ (billion $\mathrm{ft}^{2}$ or million households)

PLife $_{\mathrm{e}, \mathrm{f}, \mathrm{q}}=$ project equipment life expectancy for end-use $e$, fuel type $f$, and equipment type $q$ (years).

For new buildings:

$$
\begin{aligned}
& C R C_{e, f, q, t}=\sum_{i=\left(t-P L i f_{e, f, q}\right)}^{t} R C_{e, f, q, i}, \text { for } \mathrm{t}>\text { PLife } \\
& C R C_{e, f, q, t}=\sum_{i=1}^{t} R C_{e, f, q, i}, \text { for } \mathrm{t} \leq \text { PLife }
\end{aligned}
$$

Where $\quad \mathrm{CRC}_{\mathrm{e}, \mathrm{f}, \mathrm{q}, \mathrm{t}}=$ cumulative regional reference energy consumption in year $t$ for end-use $e$, fuel type $f$, and equipment type $q$ (TBtu)

$\mathrm{RC}_{\mathrm{e}, \mathrm{f}, \mathrm{q}, \mathrm{i}}=$ regional reference energy consumption in year $i$ for end-use $e$, fuel type $f$, and equipment type $q$ (TBtu)

PLife $_{\mathrm{e}, \mathrm{f}, \mathrm{q}}=$ project equipment life expectancy for end-use $e$, fuel type $f$, and equipment type $q$ (years).

\subsubsection{Determine Energy Consumption of Impacted Units After Project Implementation}

The performance inputs for equipment projects are defined in terms of new equipment efficiencies. A directly parallel process to that described in the previous section (2.3.3) is used to calculate consumption associated with the project equipment. In this case, the initial step uses the performance inputs for the project equipment, rather than the reference equipment efficiency:

$$
p c_{e, n f, q, t}=\frac{L_{e, t}}{p_{e, n f, q, t}}
$$

Where $\quad \mathrm{pc}_{\mathrm{e}, \mathrm{nf}, \mathrm{q}, \mathrm{t}}=$ building-level project consumption in year $t$ for end-use $e$, new fuel $n f$, and equipment type $q\left(\mathrm{kBtu} / \mathrm{ft}^{2}\right.$ or MMBtu/household)

$\mathrm{L}_{\mathrm{e}, \mathrm{t}} \quad=$ load in year $t$ for end-use $e\left(\mathrm{kBtu} / \mathrm{ft}^{2}\right.$ or MMBtu/household $)$ 


$$
\begin{aligned}
\mathrm{p}_{\mathrm{e}, \mathrm{nf}, \mathrm{q}, \mathrm{t}}= & \text { project equipment efficiency in year } t \text { for end-use } e, \text { new fuel } n f, \text { and equipment } \\
& \text { type } q(\mathrm{AFUE}, \mathrm{COP}, \mathrm{SCOP}, \text { or EF). }
\end{aligned}
$$

All other steps toward deriving cumulative regional project energy consumption, $\mathrm{CPC}$, are identical to those described in the previous section.

\subsubsection{Calculate Energy Savings}

With equipment projects, a significant probability of fuel switching exists. To calculate energy savings where the reference fuel type is the same as the buildings-related project fuel type, project consumption is subtracted from reference consumption:

$$
C E S_{e, f, q, t}=C R C_{e, f, q, t}-C P C_{e, n f, q, t}
$$

Reference fuel savings where the reference fuel type is different from the project fuel type are simply the entire reference fuel use:

$$
C E S_{e, f, q, t}=C R C_{e, f, q, t}
$$

Project fuel savings where the reference fuel type is different from the project fuel type are recorded as the negative of project consumption:

$$
C E S_{e, n f, q, t}=-C P C_{e, n f, q, t}
$$

Where $\quad \mathrm{CES}_{\mathrm{e}, \mathrm{f}, \mathrm{q}, \mathrm{t}}=$ cumulative regional energy savings in year $t$ for end-use $e$, fuel type $f$, and equipment type $q$ (TBtu)

$\mathrm{CRC}_{\mathrm{e}, \mathrm{f}, \mathrm{q}, \mathrm{t}}=$ cumulative regional reference energy consumption in year $t$ for end-use $e$, fuel type $f$, and equipment type $q$ (TBtu)

$\mathrm{CPC}_{\mathrm{e}, \mathrm{nf}, \mathrm{q}, \mathrm{t}}=$ cumulative regional project energy consumption in year $t$ for end-use $e$, new fuel $n f$, and equipment type $q$ (TBtu).

These savings (with some being negative) are combined and summed over equipment types to provide the final net energy savings by end use. The final net energy savings are aggregated by building sector, type, vintage, region, end use, and fuel type to determine the total site electric savings, total natural gas savings, and total oil savings.

\subsection{Lighting Approach}

This section addresses projects targeting lighting that are modeled in BEAMS. Lighting projects are characterized by a change in the measure of light output per unit of power, or lumens per watt.

Calculating the energy savings associated with a lighting project involves the following steps, which are discussed in the next subsections:

- Determine the size of the potential market and the number of units affected by the buildings-related project. 
- Calculate adjustments to the potential market and units affected.

- Determine the reference energy consumption of impacted units.

- Determine the energy consumption of impacted units after project implementation.

- Calculate the lighting energy savings.

- Calculate the heating and cooling interactive effects factors.

- Calculate the change in space conditioning energy use due to interactive effects.

- Derive the final energy savings.

\subsubsection{Determine Size of Potential Market and Number of Units Affected by the Buildings-Related Project}

Unlike envelope and whole-building projects, lighting projects involve equipment that fails and must be replaced during the analysis period. Despite this additional level of complexity, the initial steps are similar.

Each lighting project has a specified target market: residential and/or commercial (and their subsets), new and/or existing vintages, and north and/or south regions.

For the initial calculation, the potential market for any lighting project is, for the targeted building set, the product of the equipment stock and the reference equipment replacement factor. The equipment stock is derived by multiplying the building stock and the equipment market shares. A replacement factor is calculated as the inverse of reference equipment life, and indicates the frequency of required replacements. As indicated by the lack of a time subscript, $t$, equipment life and the associated replacement factor may not vary over the analysis period for a given end use, fuel type, and equipment type combination. The derivations of equipment stock and the potential market are shown in Equations 236 and 2-37, respectively.

$$
S E_{e, f, q, t}=S_{t} \times M_{e, f, q, t}
$$

Where $\quad \mathrm{SE}_{\mathrm{e}, \mathrm{f}, \mathrm{q}, \mathrm{t}}=$ equipment stock in year $t$ for end-use $e$, fuel type $f$, and equipment type $q$ (billion $\mathrm{ft}^{2}$ or million households)

$\mathrm{S}_{\mathrm{t}} \quad=$ building stock in year $t$ (billion $\mathrm{ft}^{2}$ or million households)

$\mathrm{M}_{\mathrm{e}, \mathrm{f}, \mathrm{q}, \mathrm{t}}=$ equipment market share in year $t$ for end-use $e$, fuel type $f$, and equipment type $q$.

$$
P M_{e, f, q, t}=S E_{e, f, q, t} \times \frac{1}{\operatorname{RLife}_{e, f, q}}=S E_{e, f, q, t} \times R R_{e, f, q}
$$

Where $\quad \mathrm{PM}_{\mathrm{e}, \mathrm{f}, \mathrm{q}, \mathrm{t}}=$ potential market in year $t$ for end-use $e$, fuel type $f$, and equipment type $q$ (billion $\mathrm{ft}^{2}$ or million households)

$\mathrm{SE}_{\mathrm{e}, \mathrm{f}, \mathrm{q}, \mathrm{t}}=$ equipment stock in year $t$ for end-use $e$, fuel type $f$, and equipment type $q$ (billion $\mathrm{ft}^{2}$ or million households)

RLife $_{\mathrm{e}, \mathrm{f}, \mathrm{q}}=$ reference equipment life expectancy for end-use $e$, fuel type $f$, and equipment type $q$ (years)

$\mathrm{RR}_{\mathrm{e}, \mathrm{f}, \mathrm{q}}=$ reference equipment replacement factor for end-use $e$, fuel type $f$, and equipment type $q$. 
To initially calculate the number of units affected by the buildings-related project, the penetration rate, or fraction of sales, is applied to the potential market, as follows:

$$
u_{e, f, q, t}=P_{e, f, q, t} \times P M_{e, f, q, t}
$$

Where $\quad \mathrm{u}_{\mathrm{e}, \mathrm{f}, \mathrm{q}, \mathrm{t}}=$ number of units affected in year $t$ for end-use $e$, fuel type $f$, and equipment type $q$ (billion $\mathrm{ft}^{2}$ or million households)

$\mathrm{P}_{\mathrm{e}, \mathrm{f}, \mathrm{q}, \mathrm{t}}=$ penetration rate in year $t$ for end-use $e$, fuel type $f$, and equipment type $q$

$\mathrm{PM}_{\mathrm{e}, \mathrm{f}, \mathrm{q}, \mathrm{t}}=$ potential market in year $t$ for end-use $e$, fuel type $f$, and equipment type $q$ (billion $\mathrm{ft}^{2}$ or million households).

In contrast to envelope and whole-building projects, the basic units calculation for lighting illustrated here does not require any special handling of existing buildings. With envelope and whole-building projects, penetration occurs against the entire building stock. For lighting, penetration occurs against only a portion of the building stock because a replacement factor is used. As a result, the existing-vintage cumulative problem described in the envelope and whole-building approach does not exist here.

\subsubsection{Calculate Adjustments to the Potential Market and Units Affected}

While this initial calculation of potential market and impacted units outlined above is fairly simple, the following steps are much more involved. Because reference equipment life and project equipment life may differ (e.g., lives of CFLs and incandescents), a project installation (unit impacted) in year $t$ may impact the potential market in future years, which in turn affects project installations in future years. Handling this issue requires an iterative process. The results of the calculations of the previous section serve as inputs to this process.

The issue of differing reference and buildings-related project lives is not the only complicating factor. The annual (rather than cumulative) nature of new building stock numbers requires unique coding to ensure recompetition of new-vintage installations upon equipment failure. This treatment renders newvintage handling consistent with that for existing buildings. Without this added treatment, new-vintage installations (whether reference equipment or project equipment) would always be replaced with like equipment upon failure, ignoring a valid possibility of additional penetration of the new technology.

Beginning with the existing-vintage case for the potential market, the calculations of this iterative updating process are outlined below as a series of conditional statements:

$$
\begin{aligned}
& P M_{e, f, q, t}= \\
& \left(\text { If }(t-1) \geq \text { RLife }_{e, f, q} \text { then } \frac{P M_{e, f, q,\left(t-R L i f e_{e, f, q}\right)}}{S E_{e, f, q,\left(t-R L i f e_{e, f, q}\right)}} \times S E_{e, f, q, t}, \text { else } P M_{e, f, q, t}\right) \\
& -\left(\text { If }(t-1) \geq \text { RLife }_{e, f, q} \text { then } \frac{u_{e, f, q,\left(t-R L i f e_{e, f, q}\right)}}{S E_{e, f, q,\left(t-R L i f e_{e, f, q}\right)}} \times S E_{e, f, q, t}, \text { else } 0\right) \\
& +\left(\text { If }(t-1) \geq \text { PLife }_{e, f, q} \text { then } \frac{u_{e, f, q,\left(t-P L i f f_{e, f, q}\right)}}{S E_{e, f, q,\left(t-P L i f e_{e, f, q}\right)}} \times S E_{e, f, q, t}, \text { else } 0\right)
\end{aligned}
$$


Where $\quad \mathrm{PM}_{\mathrm{e}, \mathrm{f}, \mathrm{q}, \mathrm{t}}=$ potential market in year $t$ for end-use $e$, fuel type $f$, and equipment type $q$ (billion $\mathrm{ft}^{2}$ or million households)

RLife $_{\mathrm{e}, \mathrm{f}, \mathrm{q}}=$ reference equipment life expectancy for end-use $e$, fuel type $f$, and equipment type $q$ (years)

PLife $_{\mathrm{e}, \mathrm{f}, \mathrm{q}}=$ project equipment life expectancy for end-use $e$, fuel type $f$, and equipment type $q$ (years)

$\mathrm{SE}_{\mathrm{e}, \mathrm{f}, \mathrm{q}, \mathrm{t}}=$ equipment stock in year $t$ for end-use $e$, fuel type $f$, and equipment type $q$ (billion $\mathrm{ft}^{2}$ or million households)

$\mathrm{u}_{\mathrm{e}, \mathrm{f}, \mathrm{q}, \mathrm{t}}=$ number of units affected in year $t$ for end-use $e$, fuel type $f$, and equipment type $q$ (billion $\mathrm{ft}^{2}$ or million households).

For new buildings:

$$
\begin{aligned}
& P M_{e, f, q, t}=\left(S E_{e, f, q, t}\right)+\left(\operatorname{If}(t-1) \geq \text { RLife }_{e, f, q} \text { then } P M_{e, f, q,\left(t-R L i f e_{e, f, q}\right.} \times\left(1-P_{e, f, q,\left(t-R L i f e_{e, f, q}\right)}\right), \text { else } 0\right) \\
& +\left(\text { If }(t-1) \geq \text { PLife }_{e, f, q} \text { then } u_{e, f, q,\left(t-P L i f e_{e, f, q}\right.}, \text { else } 0\right)
\end{aligned}
$$

Where $\quad \mathrm{PM}_{\mathrm{e}, \mathrm{f}, \mathrm{q}, \mathrm{t}}=$ potential market in year $t$ for end-use $e$, fuel type $f$, and equipment type $q$ (billion $\mathrm{ft}^{2}$ or million households)

RLife $_{\mathrm{e}, \mathrm{f}, \mathrm{q}}=$ reference equipment life expectancy for end-use $e$, fuel type $f$, and equipment type $q$ (years)

PLife $_{\mathrm{e}, \mathrm{f}, \mathrm{q}}=$ project equipment life expectancy for end-use $e$, fuel type $f$, and equipment type $q$ (years)

$\mathrm{SE}_{\mathrm{e}, \mathrm{f}, \mathrm{q}, \mathrm{t}}=$ equipment stock in year $t$ for end-use $e$, fuel type $f$, and equipment type $q$ (billion $\mathrm{ft}^{2}$ or million households)

$\mathrm{P}_{\mathrm{e}, \mathrm{f}, \mathrm{q}, \mathrm{t}}=$ penetration rate in year $t$ for end-use $e$, fuel type $f$, and equipment type $q$

$\mathrm{u}_{\mathrm{e}, \mathrm{f}, \mathrm{q}, \mathrm{t}}=$ number of units affected in year $t$ for end-use $e$, fuel type $f$, and equipment type $q$ (billion $\mathrm{ft}^{2}$ or million households).

These calculations are carried out for all years sequentially for each market segment, beginning with the first year. After the potential market is recalculated for a given year, the impacted units for that year must be recalculated, using Equation 2-38 above.

\subsubsection{Determine Reference Energy Consumption of Impacted Units}

Building-level reference energy consumption is calculated by dividing end-use loads by reference equipment efficiencies. These efficiencies represent the sales, or current-year, efficiencies of equipment that would be installed absent a buildings-related project. End-use loads represent the reference service requirements per square foot (commercial) or per household (residential) for lighting. As such, they must be divided by an efficiency to determine energy consumption:

$$
r c_{e, f, q, t}=\frac{L_{e, t}}{e_{e, f, q, t}}
$$


Where $\quad \mathrm{rc}_{\mathrm{e}, \mathrm{f}, \mathrm{q}, \mathrm{t}}=$ building-level reference consumption in year $t$ for end-use $e$, fuel type $f$, and equipment type $q\left(\mathrm{kWh} / \mathrm{ft}^{2}\right.$ or $\mathrm{MWh} /$ household $)$

$\mathrm{L}_{\mathrm{e}, \mathrm{t}} \quad=$ end-use load in year $t$ for end-use $e$ (thousand lumen-hours/ $/ \mathrm{ft}^{2}$ or million lumenhours/household)

$\mathrm{e}_{\mathrm{e}, \mathrm{f}, \mathrm{q}, \mathrm{t}}=$ reference equipment efficiency in year $t$ for end-use $e$, fuel type $f$, and equipment type $q$ (lumens/watt).

Multiplying this result by the number of impacted units yields regional reference consumption:

$$
R C_{e, f, q, t}=r c_{e, f, q, t} \times u_{e, f, q, t}
$$

Where $\quad \mathrm{RC}_{\mathrm{e}, \mathrm{f}, \mathrm{q}, \mathrm{t}}=$ regional reference consumption of impacted units in year $t$ for end-use $e$, fuel type $f$, and equipment type $q$ (billion $\mathrm{kWh}$ )

$\mathrm{rc}_{\mathrm{e}, \mathrm{f}, \mathrm{q}, \mathrm{t}}=$ building-level reference consumption in year $t$ for end-use $e$, fuel type $f$, and equipment type $q\left(\mathrm{kWh} / \mathrm{ft}^{2}\right.$ or $\mathrm{MWh} /$ household $)$

$\mathrm{u}_{\mathrm{e}, \mathrm{f}, \mathrm{q}, \mathrm{t}}=$ total number of units impacted in year $t$ for end-use $e$, fuel type $f$, and equipment type $q$ (billion $\mathrm{ft}^{2}$ or million households).

This result is converted from billion kWh to TBtu, using a standard conversion of $3412 \mathrm{Btu} / \mathrm{kWh}$.

Because the final goal is to calculate energy savings associated with impacted units, deriving total reference consumption is not necessary; rather reference consumption associated with impacted units only suffices.

At this point, the consumption figures are cumulated across years of the analysis. Each piece of equipment continues to consume energy throughout its lifetime. Therefore, in a given year, consumption may result from equipment installed in several previous years as well. The calculations, as shown in the equations below, provide aggregate energy consumption in each year, while taking into account the effect of declining building stock for existing buildings. This declining building stock acts to reduce consumption somewhat over time. To compare the reference and project equipment's energy usage appropriately, the reference consumption is cumulated over the lifetime of the project equipment. For existing buildings:

$$
\begin{aligned}
& C R C_{e, f, q, t}=\sum_{i=\left(t-P L i f_{e, f, q}\right)}^{t} R C_{e, f, q, i} \times \frac{S_{t}}{S_{i}}, \text { for } \mathrm{t}>\text { PLife } \\
& C R C_{e, f, q, t}=\sum_{i=1}^{t} R C_{e, f, q, i} \times \frac{S_{t}}{S_{i}}, \text { for } \mathrm{t} \leq \text { PLife }
\end{aligned}
$$

Where $\quad \mathrm{CRC}_{\mathrm{e}, \mathrm{f}, \mathrm{q}, \mathrm{t}}=$ cumulative regional reference energy consumption in year $t$ for end-use $e$, fuel type $f$, and equipment type $q$ (TBtu)

$\mathrm{RC}_{\mathrm{e}, \mathrm{f}, \mathrm{q}, \mathrm{i}}=$ regional reference energy consumption in year $i$ for end-use $e$, fuel type $f$, and equipment type $q$ (TBtu)

$\mathrm{S}_{\mathrm{t}} \quad=$ building stock in year $t$ (billion $\mathrm{ft}^{2}$ or million households)

$\mathrm{S}_{\mathrm{i}} \quad=$ building stock in year $i$ (billion $\mathrm{ft}^{2}$ or million households) 


$$
\begin{aligned}
\text { PLife }_{\mathrm{e}, \mathrm{f}, \mathrm{q}}= & \text { project equipment life expectancy for end-use } e \text {, fuel type } f \text {, and equipment type } q \\
& \text { (years). }
\end{aligned}
$$

For new buildings:

$$
\begin{aligned}
& C R C_{e, f, q, t}=\sum_{i=\left(t-P L i f_{e, f, q}\right)}^{t} R C_{e, f, q, i}, \text { for } \mathrm{t}>\text { PLife } \\
& C R C_{e, f, q, t}=\sum_{i=1}^{t} R C_{e, f, q, i}, \text { for } \mathrm{t} \leq \text { PLife }
\end{aligned}
$$

Where $\quad \mathrm{CRC}_{\mathrm{e}, \mathrm{f}, \mathrm{q}, \mathrm{t}}=$ cumulative regional reference energy consumption in year $t$ for end-use $e$, fuel type $f$, and equipment type $q$ (TBtu)

$\mathrm{RC}_{\mathrm{e}, \mathrm{f}, \mathrm{q}, \mathrm{i}}=$ regional reference energy consumption in year $i$ for end-use $e$, fuel type $f$, and equipment type $q$ (TBtu)

PLife $_{\mathrm{e}, \mathrm{f}, \mathrm{q}}=$ project equipment life expectancy for end-use $e$, fuel type $f$, and equipment type $q$ (years).

\subsubsection{Determine Energy Consumption of Impacted Units After Project Implementation}

The performance inputs for lighting projects are defined in terms of new equipment efficiencies. A directly parallel process to that described in the previous section (2.4.3) is used to calculate consumption associated with the project equipment. In this case, the initial step uses the performance inputs for the project equipment, rather than the reference equipment efficiency:

$$
p c_{e, f, q, t}=\frac{L_{e, t}}{p_{e, f, q, t}}
$$

Where $\quad \mathrm{pc}_{\mathrm{e}, \mathrm{f}, \mathrm{q}, \mathrm{t}}=$ building-level project consumption in year $t$ for end-use $e$, fuel type $f$, and equipment type $q\left(\mathrm{kWh} / \mathrm{ft}^{2}\right.$ or $\mathrm{MWh} /$ household $)$

$\mathrm{L}_{\mathrm{e}, \mathrm{t}} \quad=$ load in year $t$ for end-use $e$ (thousand lumen-hours $/ \mathrm{ft}^{2}$ or million lumenhours/household)

$\mathrm{p}_{\mathrm{e}, \mathrm{f}, \mathrm{q}, \mathrm{t}}=$ project equipment efficiency in year $t$ for end-use $e$, fuel type $f$, and equipment type $q$ (lumens/watt).

All other steps toward deriving cumulative regional project energy consumption, $\mathrm{CPC}$, are identical to those described in the previous section.

\subsubsection{Calculate Lighting Energy Savings}

Unlike equipment projects, where a significant probability of fuel switching exists, the lighting case is more straightforward. To calculate lighting energy savings, project consumption is subtracted from reference consumption:

$$
C E S_{e, f, q, t}=C R C_{e, f, q, t}-C P C_{e, f, q, t}
$$


Where $\quad \mathrm{CES}_{\mathrm{e}, \mathrm{f}, \mathrm{q}, \mathrm{t}}=$ cumulative regional energy savings in year $t$ for end-use $e$, fuel type $f$, and equipment type $q$ (TBtu)

$\mathrm{CRC}_{\mathrm{e}, \mathrm{f}, \mathrm{q}, \mathrm{t}}=$ cumulative regional reference energy consumption in year $t$ for end-use $e$, fuel type $f$, and equipment type $q$ (TBtu)

$\mathrm{CPC}_{\mathrm{e}, \mathrm{f}, \mathrm{q}, \mathrm{t}}=$ cumulative regional project energy consumption in year $t$ for end-use $e$, fuel $f$, and equipment type $q$ (TBtu).

\subsubsection{Calculate Heating and Cooling Interactive Effects Factors}

A change in lighting consumption significantly impacts other end uses as well, due to the fact that lights produce heat. As more efficient lighting or lighting load reductions are incorporated in buildings, heating loads can be expected to increase, while cooling loads should be reduced. These interactions are accounted for through the development and use of lighting interaction factors. BEAMS incorporates interactive effects coefficients as inputs, which are used to derive heating and cooling load change factors. The following two sections discussing the derivation of interactive effects coefficients are identical to those included in the envelope and whole-building project discussion, and are included here for the sake of completeness.

\subsubsection{Derivation of the Interactive Effects Coefficients-Reference}

Reference loads were determined using NEMSFEDS, an iteration tool based on FEDS that allows a single case to be modified and run (loads only) by altering inputs to a [casename].ini file. In this manner a single case can be used to run a multi-dimensional matrix of all combinations of building type, size, vintage, location, occupancy, and lighting configurations. Statistical data of actual building size and vintage information were then used to combine the NEMSFEDS results into a location by building type results matrix where each building type is of the weighted average size and weighted average vintage (for existing) or 2000 vintage for new buildings.

Values were determined for all combinations of the following:

- commercial, residential, and industrial building types

- new and existing buildings

- nine census regions (and north and south for BEAMS).

\subsubsection{Derivation of the Interactive Effects Coefficients-Variation from Reference}

Lighting consumption was decreased from $100 \%$ to $0 \%$ with $10 \%$ steps. As a result of the decrease in lighting consumption, the heating load increased and the cooling load decreased. The fractional increases in the heating load and fractional decreases in the cooling load were then determined at each of the steps. Lastly, the results were converted via regression to equations (one for heating and one for cooling for each combination of building type, new/existing, and location) where the only input is the lighting consumption reduction percentage. The regression equations are of the form:

$$
\begin{aligned}
& \Delta \text { heat }=a \times \Delta L^{b} \\
& \Delta \text { cool }=c \times \Delta L^{2}+d \times \Delta L
\end{aligned}
$$


Where $a, b, c$, and $d$ are the interactive effects coefficients
$\Delta$ heat $=$ the fractional change in heating load
$\Delta$ cool $=$ the fractional change in cooling load
$\Delta \mathrm{L}=$ the lighting consumption reduction percentage.

\subsubsection{Specification of the Lighting Consumption Reduction Percentage}

For projects that replace lighting technologies, the lighting consumption reduction percentage is defined as the percentage of the total lighting electricity consumption that is reduced across all lighting technologies (it assumes all buildings within a certain type, vintage, and region get the buildings-related technology). Hence, if there is only one existing technology in the buildings, then the percentage of the technology being replaced is $100 \%$ for that portion of the buildings being penetrated in that year (the penetration rate), and the lighting consumption reduction percentage is determined from the change in efficacy as:

$$
\Delta L=\left(1-\frac{\text { old efficacy }}{\text { newefficacy }}\right) \times 100
$$

Normally, buildings have more than one lighting technology present and hence we must also account for the consumption of the lighting technologies that are not being replaced. In this case the lighting consumption reduction percentage is calculated from the change in the weighted average efficacy as:

$$
\Delta L=\left(1-\frac{\sum_{\text {alli }}\left(\frac{1}{\text { newefficacy }_{i}} \times \text { share }_{i}\right)}{\sum_{\text {all } i}\left(\frac{1}{\text { old efficacy }_{i}} \times \text { share }_{i}\right)}\right) \times 100
$$

Where $i$ represents existing (or replaced/penetrated) equipment types.

In the case of unreplaced technologies, new and old efficacies are equal. This lighting consumption reduction percentage $(\Delta \mathrm{L})$ is input into the $\Delta$ heat and $\Delta$ cool equations, yielding the heating and cooling interactive effects factors.

\subsubsection{Calculation of Interactive Effects Factors}

Taking the general formulation provided in the section above and applying it to the specific case of lighting projects in BEAMS, the lighting consumption reduction percentage is calculated as:

$$
\Delta L_{t}=\left(1-\frac{\frac{1}{p_{q^{*}, t}} \times M_{q^{*}, t}+\sum_{q \neq q^{*}}\left(\frac{1}{e_{q, t}} \times M_{q, t}\right)}{\sum_{\text {all } q}\left(\frac{1}{e_{q, t}} \times M_{q, t}\right)}\right) \times 100
$$


Where $\Delta \mathrm{L}_{\mathrm{t}} \quad=$ the lighting consumption reduction percentage in year $t$

$\mathrm{p}_{\mathrm{q}^{*}, \mathrm{t}} \quad=$ project equipment efficiency in year $t$ for penetrated equipment type $q^{*}$ (lumens/watt)

$\mathrm{M}_{\mathrm{q}^{*}, \mathrm{t}} \quad=$ equipment market share in year $t$ for penetrated equipment type $q^{*}$

$\mathrm{e}_{\mathrm{q}, \mathrm{t}} \quad=$ reference equipment efficiency in year $t$ for equipment type $q$ (lumens/watt)

$\mathrm{M}_{\mathrm{q}, \mathrm{t}} \quad=$ equipment market share in year $t$ for equipment type $q$.

Note that while efficiencies and market shares are also broken out by end use and fuel type within BEAMS, in this particular case only lighting and electricity are relevant.

At this point, the required components for calculating the interactive effects factors are available. Using Equations 2-49 and 2-50, year-specific factors $\Delta$ heat $t_{\mathrm{t}}$ and $\Delta \operatorname{cool}_{\mathrm{t}}$ are computed. During these calculations, a constraint is placed on $\Delta \mathrm{cool}_{\mathrm{t}}$. While it is theoretically possible for a heating load to increase by more than $100 \%$ as a result of a lighting efficiency project, it is not possible to eliminate more than an entire cooling load. As a result, if $\Delta \operatorname{cool}_{t}<-1$, it is set to -1 .

\subsubsection{Calculate Change in Space Conditioning Energy Use Due to Interactive Effects}

The first step necessary to derive actual space conditioning energy impacts via the use of the interactive effects factors is to calculate an appropriate measure of impacted units (billion $\mathrm{ft}^{2}$ or million households). This process is nearly identical to that undertaken earlier for direct lighting impacts in Sections 2.4.1 and 2.4.2. The unique aspect in this case is that, unlike before, market share is "backed out" of, or not included, in the calculation. The assumption driving this is that HVAC interactive effects impact an entire building, rather than just the area served by the penetrated lighting technology. As a result, the expanded potential market is:

$$
E P M_{e, f, q, t}=S_{t} \times{\frac{1}{\text { Life }_{e, f, q}}}_{=}=S_{t} \times R R_{e, f, q}
$$

Where $\quad \mathrm{EPM}_{\mathrm{e}, \mathrm{f}, \mathrm{q}, \mathrm{t}}=$ expanded potential market in year $t$ for end-use $e$, fuel type $f$, and equipment type $q$ (billion $\mathrm{ft}^{2}$ or million households)

$\mathrm{S}_{\mathrm{t}} \quad=$ building stock in year $t$ (billion $\mathrm{ft}^{2}$ or million households)

RLife $_{\mathrm{e}, \mathrm{f}, \mathrm{q}}=$ reference equipment life expectancy for end-use $e$, fuel type $f$, and equipment type $q$ (years)

$\mathrm{RR}_{\mathrm{e}, \mathrm{f}, \mathrm{q}}=$ reference equipment replacement factor for end-use $e$, fuel type $f$, and equipment type $q$.

To initially calculate the expanded number of units impacted, the penetration rate, or fraction of sales, is applied to the expanded potential market, as follows:

$$
E u_{e, f, q, t}=P_{e, f, q, t} \times E P M_{e, f, q, t}
$$


Where $\quad \mathrm{Eu}_{\mathrm{e}, \mathrm{f}, \mathrm{q}, \mathrm{t}} \quad=$ expanded number of units impacted in year $t$ for end-use $e$, fuel type $f$, and equipment type $q$ (billion $\mathrm{ft}^{2}$ or million households)

$\mathrm{P}_{\mathrm{e}, \mathrm{f}, \mathrm{q}, \mathrm{t}}=$ penetration rate in year $t$ for end-use $e$, fuel type $f$, and equipment type $q$

$\mathrm{EPM}_{\mathrm{e}, \mathrm{f}, \mathrm{q}, \mathrm{t}}=$ expanded potential market in year $t$ for end-use $e$, fuel type $f$, and equipment type $q$ (billion $\mathrm{ft}^{2}$ or million households).

As with the direct lighting impacts, adjustments to the potential market and units impacted are required. The necessary steps are identical to those outlined in Section 2.4.2.

The descriptors for the resulting array, $\mathrm{Eu}_{\mathrm{e}, \mathrm{f}, \mathrm{q}, \mathrm{t}}$, are associated with the lighting project, rather than the interactive effects load reductions. In other words, the array is broken out by lighting, electricity, and the penetrated lighting equipment types. Currently with BEAMS, lighting projects penetrate against only one type of equipment. As a result, only one combination of end use, fuel type, and penetrated equipment is present in the descriptor set. Thus, no aggregation over equipment types is necessary to transform the array into a usable form for calculation of the load reductions due to interactive effects.

$$
I u_{t}=E u_{e, f, q, t}
$$

Where $\quad \mathrm{Iu}_{\mathrm{t}} \quad=$ number of units affected by interactive effects in year $t$ (billion $\mathrm{ft}^{2}$ or million households)

$\mathrm{Eu}_{\mathrm{e}, \mathrm{f}, \mathrm{q}, \mathrm{t}}=$ expanded number of units affected in year $t$ for end-use $e$, fuel type $f$, and equipment type $q$ (billion $\mathrm{ft}^{2}$ or million households).

The load changes from interactive effects are calculated by applying the interactive effects factors to loads. This step shares some similarities with the procedures outlined in the section on whole building and envelope projects. As noted earlier, as lighting efficiency increases, cooling loads decrease and heating loads increase. As a result, the calculated values for $\Delta$ heat are positive, and those for $\Delta$ cool are negative. Because the load reduction, rather than the change in load, is the desired output, a sign change is applied in the following calculation:

For heating:

$$
I l r_{e, t}=L_{e, t} \times\left(-\Delta h e a t_{t}\right)
$$

For cooling:

$$
I l r_{e, t}=L_{e, t} \times\left(-\Delta \operatorname{cool}_{t}\right)
$$

Where $\quad \mathrm{Ilr}_{\mathrm{e}, \mathrm{t}} \quad=$ building-level load reduction in year $t$ for end-use $e$, due to interactive effects $\left(\mathrm{kBtu} / \mathrm{ft}^{2}\right.$ or MMBtu/household)

$\mathrm{L}_{\mathrm{e}, \mathrm{t}} \quad=$ load in year $\mathrm{t}$ for end-use $e\left(\mathrm{kBtu} / \mathrm{ft}^{2}\right.$ or MMBtu/household $)$

$\Delta$ heat $_{\mathrm{t}}=$ the fractional change in heating load (or the heating interactive effects factor) in year $t$

$\Delta \operatorname{cool}_{\mathrm{t}}=$ the fractional change in cooling load (or the cooling interactive effects factor) in year $t$. 
The building-level load reductions are translated into regional load reductions as follows:

$$
I L R_{e, t}=I l r_{e, t} \times I u_{t}
$$

Where $\quad \mathrm{ILR}_{\mathrm{e}, \mathrm{t}}=$ regional load reduction in year $t$ for end-use $e$, due to interactive effects (TBtu)

$\mathrm{Ilr}_{\mathrm{e}, \mathrm{t}}=$ building-level load reductions in year $t$ for end-use $e$, due to interactive effects $\left(\mathrm{kBtu} / \mathrm{ft}^{2}\right.$ or MMBtu/household)

$\mathrm{Iu}_{\mathrm{t}} \quad=$ number of units affected by interactive effects in year $t$ (billion $\mathrm{ft}^{2}$ or million households).

At this point, the load reductions are cumulated across years of the analysis. Each piece of new lighting equipment continues to save energy throughout its lifetime, and with those continued savings come load reductions due to interactive effects. Therefore, in a given year, such load reductions may result from lighting equipment installed in several previous years as well. The calculations, as shown in the equations below, provide aggregate load reductions in each year, while taking into account the effect of declining building stock for existing buildings. This declining building stock acts to reduce the load reductions somewhat over time. The load reductions are cumulated over the lifetime of the lighting project equipment. For existing buildings:

$$
\begin{aligned}
& \operatorname{CILR}_{e, t}=\sum_{i=\left(t-P L i f_{e, f, q}\right)}^{t} I L R_{e, i} \times \frac{S_{t}}{S_{i}}, \text { for } \mathrm{t}>\text { PLife } \\
& C I L R_{e, t}=\sum_{i=1}^{t} I L R_{e, i} \times \frac{S_{t}}{S_{i}}, \text { for } \mathrm{t} \leq \text { PLife }
\end{aligned}
$$

Where $\quad$ CILR $_{\mathrm{e}, \mathrm{t}}=$ cumulative regional load reduction in year $t$ for end-use $e$, due to interactive effects (TBtu)

$\mathrm{ILR}_{\mathrm{e}, \mathrm{i}}=$ regional load reduction in year $i$ for end-use $e$, due to interactive effects (TBtu)

$\mathrm{S}_{\mathrm{t}} \quad=$ building stock in year $t$ (billion $\mathrm{ft}^{2}$ or million households)

$\mathrm{S}_{\mathrm{i}} \quad=$ building stock in year $i$ (billion $\mathrm{ft}^{2}$ or million households)

PLife $_{\mathrm{e}, \mathrm{f}, \mathrm{q}}=$ lighting project equipment life expectancy for end-use $e$, fuel type $f$, and equipment type $q$ (years).

For new buildings:

$$
\begin{aligned}
& C I L R_{e, t}=\sum_{i=\left(t-P L i f_{e}, f, q\right.}^{t} I L R_{e, i}, \text { for } \mathrm{t}>\text { PLife } \\
& C I L R_{e, t}=\sum_{i=1}^{t} I L R_{e, i}, \text { for } \mathrm{t} \leq \text { PLife }
\end{aligned}
$$

Where $\quad$ CILR $_{\mathrm{e}, \mathrm{t}}=$ cumulative regional load reduction in year $t$ for end-use $e$, due to interactive effects (TBtu)

$\operatorname{ILR}_{\mathrm{e}, \mathrm{f}, \mathrm{q}, \mathrm{i}}=$ regional load reduction in year $i$ for end-use $e$, due to interactive effects (TBtu)

PLife $_{\mathrm{e}, \mathrm{f}, \mathrm{q}}=$ lighting project equipment life expectancy for end-use $e$, fuel type $f$, and equipment type $q$ (years). 
Earlier a constraint was placed on $\Delta \operatorname{cool}_{t}$, to eliminate the unreasonable outcome of eliminating more than an entire cooling load due to interactive effects. At this point it is necessary to implement a reality check on both heating and cooling, as the magnitude of the heating and cooling load changes can not exceed the magnitude of the aggregated-to-end-use level lighting consumption change, obtained from the results calculated earlier in equation 2-48. As mentioned earlier in this section, the presence of only one combination of fuel type and penetrated equipment type renders aggregation to the end-use level unnecessary.

For heating:

$$
\text { If }\left|\mathrm{CES}_{\text {light, } \mathrm{t}}\right|<\left|C I L R_{e, t}\right| \text { then } \operatorname{CILR}_{e, t}=-\mathrm{CES}_{\text {light }, \mathrm{t}}
$$

For cooling:

$$
\text { If }\left|\mathrm{CES}_{\text {light }, \mathrm{t}}\right|<\left|\operatorname{CILR}_{e, t}\right| \text { then } C I L R_{e, t}=\mathrm{CES}_{\text {light }, \mathrm{t}}
$$

Where $\quad \mathrm{CES}_{\text {light, }}=$ cumulative regional energy savings in year $t$ for lighting (TBtu)

$\mathrm{CILR}_{\mathrm{e}, \mathrm{t}}=$ cumulative regional load reductions in year $t$ for end-use $e$, due to interactive effects (TBtu).

These load reductions must be translated into energy savings. To do this, reference assumptions regarding existing equipment efficiencies and existing equipment market shares are used. First, the load reductions resulting from interactive effects are divided by the reference (existing) equipment efficiencies, or stock efficiencies, which yields potential energy savings by equipment type, end use, and fuel type. Stock efficiencies are appropriate here because the lighting project does not replace any HVAC equipment, and thus the lighting project interacts with the stock of HVAC equipment in place. (In the case of new buildings, stock and sales efficiencies are identical in BEAMS). The potential energy savings assume that each equipment type has $100 \%$ of the market, so the actual equipment market shares must then be applied. The market share for each equipment type is multiplied by the potential energy savings to determine the actual energy savings. Equation 2-66 illustrates the calculations:

$$
I E S_{e, f, q, t}=\frac{C I L R_{e, t}}{e_{e, f, q, t}} \times M_{e, f, q, t}
$$

Where $\quad \mathrm{IES}_{\mathrm{e}, \mathrm{f}, \mathrm{q}, \mathrm{t}}=$ energy savings in year $t$ due to interactive effects for end-use $e$, fuel type $f$, and equipment type $q$ (TBtu)

$\mathrm{CILR}_{\mathrm{e}, \mathrm{t}}=$ cumulative regional load reductions in year $t$ due to interactive effects for end-use $e$ (TBtu)

$\mathrm{e}_{\mathrm{e}, \mathrm{f}, \mathrm{q}, \mathrm{t}}=$ reference equipment efficiency in year $t$ for end-use $e$, fuel type $f$, and equipment type $q$ (AFUE, COP, or SCOP)

$\mathrm{M}_{\mathrm{e}, \mathrm{f}, \mathrm{q}, \mathrm{t}}=$ equipment market share in year $t$ for end-use $e$, fuel type $f$, and equipment type $q$. 


\subsubsection{Derive Final Energy Savings}

The lighting energy savings and the space-conditioning energy savings are combined and summed over equipment types to provide the final net energy savings by end use. The final net energy savings are aggregated by building sector, type, vintage, region, end use, and fuel type to determine the total site electric savings, total natural gas savings, and total oil savings.

\subsection{Other Components}

This section addresses calculations made within BEAMS subsequent to the energy algorithms described in previous sections. Each of the following computations applies not only to BEAMSestimated projects but also to projects with savings estimated with NEMS-PNNL or using spreadsheet models. For projects estimated by methods other than BEAMS, site energy savings, investment, and any non-energy costs are first imported into BEAMS. These inputs are broken out by building sector, type, vintage, region, and year, as are all final outputs of the calculations described below.

\subsubsection{Calculate Primary Energy Savings}

For BEAMS-estimated projects, site energy savings are calculated using the algorithms presented in previous sections. As mentioned above, for other projects, site energy savings are provided to BEAMS as an input. Total site energy consists of site electric, natural gas, fuel oil, and "other" fuel savings. To derive primary electric savings, the site electric savings are multiplied by a year-specific electricity conversion factor within BEAMS. Primary non-electric savings consist of the sum of natural gas, oil, and other fuel savings. Summation of primary electric and primary non-electric savings yields the total net primary energy savings. The units for all of these data are TBtu. These data are provided both at the enduse level and in more aggregated form.

\subsubsection{Calculate Emissions Reductions and Energy Cost Savings}

BEAMS input data include energy prices and site-energy emission factors, both of which are building sector-, fuel- (electric, gas, and oil), and year-specific. Emission factors are included for carbonequivalent emissions, sulfur dioxide, nitrous oxides, volatile organic compounds, particulate matter, and carbon monoxide. Factors are multiplied by site energy savings, and prices are multiplied by the respective fuel savings. The resulting energy cost savings are reported in millions of dollars, and the emissions reductions are represented as millions of metric tons (MMton) avoided. These energy cost savings are gross savings. That is, the required incremental investment cost is not subtracted from the gross energy cost savings. These data are provided both at the end-use level and in more aggregated form.

\subsubsection{Determine Required Investment and Non-energy Costs}

For projects estimated outside of BEAMS, investment and non-energy costs are provided as an input to BEAMS. For BEAMS-estimated projects, investment and non-energy costs are output as part of the process, and their estimation relies on the installed units calculated in the above algorithms. These units are in terms of either million households (residential), or billion square feet (commercial). Per-unit equipment costs (dollars per square foot or dollars per household) are multiplied by installed units, as Equation 2-67 shows: 


$$
I_{t}=c_{t} \times u_{t}
$$

Where $\mathrm{I}_{\mathrm{t}} \quad=$ investment in year $t$

$\mathrm{c}_{\mathrm{t}} \quad=$ per-unit installed cost in year $t$

$\mathrm{u}_{\mathrm{t}} \quad=$ number of units impacted in year $t$.

Similarly, non-energy costs are calculated as follows:

$$
N E_{t}=n e_{t} \times u_{t}
$$

Where $\mathrm{NE}_{\mathrm{t}} \quad=$ non-energy cost in year $t$

$\mathrm{ne}_{\mathrm{t}} \quad=$ per-unit non-energy cost in year $t$

$\mathrm{u}_{\mathrm{t}} \quad=$ number of units impacted in year $t$.

Each of these calculations is performed for reference costs, project costs, and the incremental costs. After necessary conversions, the resulting investment and non-energy costs are reported in millions of dollars. 



\subsection{References}

Bass, FM. 1969. “A New Product Growth Model for Consumer Durables.” Management 15:215-227.

Elliott DB, DM Anderson, DB Belzer, KA Cort, JA Dirks, and DJ Hostick. 2004a. Baseline Inputs for BEAMS: Data Used in Preparing Methodological Framework for Analysis of Building-Related

Programs: The GPRA Metrics Effort, June 2004. PNNL-14696, Pacific Northwest National Laboratory, Richland, WA. http://www.pnl.gov/main/publications/external/technical_reports/PNNL-14696.pdf

Elliott DB, DM Anderson, DB Belzer, KA Cort, JA Dirks, and DJ Hostick. 2004b. Methodological Framework for Analysis of Buildings-Related Programs: The GPRA Metrics Effort. PNNL-14697, Pacific Northwest National Laboratory, Richland, WA.

http://www.pnl.gov/main/publications/external/technical_reports/PNNL-14697.pdf 




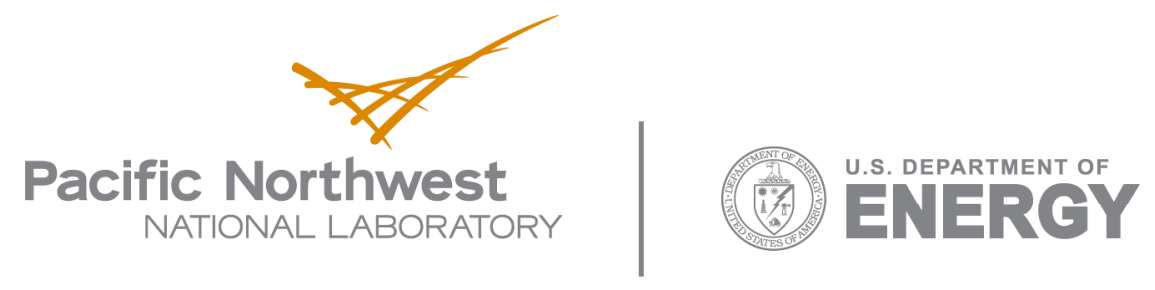

902 Battelle Boulevard

P.O. Box 999

Richland, WA 99352

1-888-375-PNNL (7665)

www.pnl.gov 